\title{
Socio-economic characteristics of the community that determine ability to uptake precautionary measures to mitigate flood disaster in Kano Plains, Kisumu County, Kenya
}

\author{
Joyce Okayo ${ }^{*}$, Peter Odera and Stanley Omuterema
}

\begin{abstract}
Background: Kano Plains, Kisumu County, Kenya experiences more severe river floods which is slow onset and predictable. The cost of annual relief and rehabilitation measures in Kano Plains alone is estimated at Kshs 57 million or US\$600,000. This is attributed to the fact that since disasters do not occur frequently, people feel highly burdened to participate in community-based disaster preparedness activities during normal times when nothing happens. In this context, perceived risk does not contribute directly to taking protective responses. Thus, the socio-economic characteristics of the community and how these influence uptake of precautionary measures is the subject of inquiry in this paper.

Results: The data for the study were collected through a survey of 384 households, five focus group discussions, and 21 key informant interviews. Descriptive analysis and frequency distribution were used to describe the data. Chi-Square test to determine the strength of the association between the variables and uptake of precautionary measures suggests no significant difference between education level and uptake. Binary logistic regression showed a significant difference on low uptake between those who lived within $2 \mathrm{Kms}$ of River Nyando compared to those who lived more than $2 \mathrm{Kms}$ from the river.

Conclusions: Findings confirmed that high level of uptake of precautionary measures was dependent on distance, household composition, income, occupation of the household and social network type. It is hoped that these findings will encourage the government of Kenya to develop a policy that specifically informs residents of the flood prone areas on allowable distance from the river to where houses can be erected because some precautionary measures the households have employed involved moving to higher grounds.
\end{abstract}

Keywords: Socio-economic, Uptake, Precautionary measures, Flood disaster mitigation, Kano Plains, Kenya

* Correspondence: joy.okayo@gmail.com

Masinde Muliro University of Science and Technology, P.O. Box 190-50100, Kakamega, Kenya 


\section{Background}

Over the past decades, the pattern of floods across all continents has been changing, becoming more frequent, intense and unpredictable for local communities, particularly as issues of development and poverty have led more people to live in areas vulnerable to flooding (Terumoto 2006). Floods are the most reoccurring, widespread, disastrous and frequent natural hazards of the world (Aloysius 2012). Flooding accounts for approximately one third of all natural disasters in both the developed and developing worlds (United Nations International Strategy for Disaster Risk Reduction/UNISDR 2012).

According to World Disasters Report (WDR) (2014), in 2013, floods accounted for $44 \%$ of deaths caused by natural hazards -more than any other natural hazard, including storms, which accounted for $41 \%$. Almost 100 million people were affected by disasters in 2013 and by far the worst affected region of the world was Asia with a staggering $87 \%$ of those affected by disasters in 2013 . Most deaths were caused by floods, and natural hazards caused losses estimated at 118.6 billion US dollars in 2013, the fourth lowest of the decade.

The potential consequences of floods are profound, particularly on people in the less developed countries of the world, such as Africa, Asia, and Latin America (Adedeji et al. 2012). Almost two (2) billion people were affected by disasters in the last decade of the 20th century. Eighty-six percent (86\%) of these were floods and droughts (United Nations Environment Programme/UNEP 2006). Much of flooding in Africa has been attributed to global warming (British Broadcasting Corporation (BBC) 2007 and National Geographic News NGN) 2007) and this is characterized by extreme hydro-meteorological events, which will likely increase in frequency and magnitude due to climate change.

Most parts of the sub-Saharan Africa (SSA) are vulnerable to flooding with East, South and Central regions having the most prevalent flood disaster, followed by West Africa (Ngoran et al. 2015). Burkina Faso, Chad, Ethiopia, Ghana, Senegal, Sudan, Togo, Kenya, Liberia, Mali, Niger, Rwanda, Malawi, Mozambique, Nigeria and Uganda are the worst hit by floods in SSA, affecting farmlands, settlements and other ecosystem services. The worst single flood incidents in SSA happened in East Africa: one incident in 1997 slew 2,311 people in Somalia; and another in 1999 affected 1.8 million people in Sudan. Sub-Saharan Africa's disaster profile is closely linked to the vulnerability of its population and economy and their often-low capacities to cope with natural hazards. For example, in Madagascar, Post Disaster Needs Assessment (PDNA) indicates some losses were avoidable and often caused by weak housing and construction standards. Following a disaster, poor populations often have no other option than to carry out sub-standard reconstruction and resettlement in high-risk areas. Most responses address only one type of hazard or economic sector such as urban floods in Senegal, or droughts in Ethiopia. This is approach is comparable to disaster response in Kano Plains where a number of projects only address one type of hazard: floods. In this area, the limited intervention for disaster risk reduction has consisted mainly of conventional methods such as structural techniques and the provision of relief (Nyakundi et al. 2010). This study and Nyakundi et al. (2010) indicate a growing belief and dependency on technical approach such as dykes seemingly to be the only method to control the floods. Awareness of other measures for flood mitigation such as public education is still very low.

In Kenya, floods are the most common climatic disasters and the leading hydro-meteorological disaster in East Africa. During the last couple of decades, Kenya has experienced serious incidents of flood disaster, in different parts of the country and caused major disturbances, destroying property and resulting in loss of life. Floods occur due to natural factors like flash floods, river floods and coastal floods. They may also occur due to human manipulation of watersheds, drainage basins and flood plains. For example, in some cases floods have occurred in the river basins even with normal rains because of excess surface water runoff occasioned by deforestation, land degradation upstream. Kenya is affected by floods following torrential rainfall (United Nations Development Program/UNDP 2009). These force thousands of people living in the lowlands to move to higher grounds. The people affected are mostly in western and Nyanza provinces and in Tana River district.

Regionally, Kenya has a very high hazard risk, standing at $6.2 \%$ on risk index against Somalia $8.8 \%$; Democratic Republic of Congo 7 \%; Ethiopia and Uganda $6.4 \%$; Burundi 5.4 \%; Tanzania $5.3 \%$ and Rwanda $4.1 \%$. For a period running 24 years: 1990-2014, its percentage loss attributed to flood disaster is $71.9 \%$ compared to drought $17.5 \%$; and landslide $7 \%$; while combined economic loss attributed to floods stands at $93 \%$ against 19.9 \% of landslide (Kenya Disaster and Risk Profile 2014). Average annual loss as a result of floods was $87.8 \%$ against $12.2 \%$ Earthquake. Floods related fatalities constitute a whopping $60 \%$ of disaster victims in Kenya (Huho and Kosonei 2014; Otiende 2009). The cost of annual relief and rehabilitation measures in Kano Plains alone is estimated at Kshs 57 million or US\$ 600,000 . This is attributed to the fact that since disasters do not occur frequently, people feel highly burdened to participate in community-based disaster preparedness activities during normal times when nothing happens. Thus, perceived risk does not contribute directly to taking protective responses. 
In Kenya today- October, 2015, flood is a national issue and worse with the prediction of El Niño that is anticipated in most regions with direct effects of increased surface water levels leading to flooding of lowlying land and roads, as well as increasing the risk of groundwater flooding (Orengo 2015). The government has set aside Kshs 5 billion for exigencies and more than 70,000 National Youth Service personnel will be on standby in case of emergencies. The funds will be allocated to infrastructure, agriculture and relocation of people from areas prone to mudslides and floods. The preparation being undertaken by various counties is to mitigate the effects of the anticipated El Niño floods having witnessed devastating floods in the country in January-April 2015.

In April-May 2015, flash floods hit Kenya, more so in places that had never experienced floods before. For example, Nairobi Central Business District and residential areas (Kileleshwa, Loresho, South C, Nyayo High Rise, Clay Works, Imara Daima, and Nairobi West); Narok; Siaya; Kajiado; Homa Bay and Mandera. The flash flood had devastating effect on people and property: buildings collapsed, roads became impassable, and many were injured and died. In Nairobi, a building collapsed in Mukuru Fuata Nyayo area of South B and the flood also caused chaos on the city's roads during the course of the day. Over 40 people died when a bus was swept away by a swollen seasonal river at Gaduda, about $35 \mathrm{~km}$ from Mandera Town in mid April. On the $28^{\text {th }}$ April, 2015, the streets of Narok town were turned to rivers after a massive downpour killing about 15 people (Breaking News Kenya 2015). The flash floods that hit various towns indicate that climate-related disasters are unpredictable and preparation and mitigation are the cornerstone of management.

There has been and still there is poor drainage in the slums of Nairobi and the banks of Nairobi river. In Kibera slums of Nairobi, the confluence between the Mutoine and Ngong rivers as they flow into the Nairobi Dam in the east turns into a raging flood plain that causes destruction to parts of Gatwekera and Kisumu villages each (Achuka 2015). These rivers have had histories of bursting their banks during the rainy season. For instance at Magiwa Estate in Mbagathi, the drainage system that got blocked in May 2015 has not been repaired and yet El Niño flood is anticipated any time now this October, 2015. There is still no evidence of any preparedness activities carried out in the slum area. They say they are not moving; waiting for the government to offer relief supplies. This behaviour is likened to the residents of Kano Plains who know very well that a flood event in the area is very destructive and they should heed early warning of the impending flood and move to evacuation centres/to safer grounds but hold on till the eleventh hour and publicly announce to the world that they are in danger. Reports indicate that in May and June 2015 Nairobi city suffered flash floods that caught the county government unawares and left a huge trail of destruction, claiming lives, damaging roads and property (Achuka 2015).

In Western Kenya, Nyando, Nyakach, Muhoroni and parts of Kisumu East sub-county are usually affected by floods (Onyango 2015) and this trend is increasingly becoming a major concern to the country's socioeconomic development due to the substantial economic and financial losses incurred to respond to frequent flood disasters (Otiende 2009). The most affected areas are the low lying areas of the country located in Kenya's five drainage basins with Lake Victoria Basin being the most affected. In Nyando sub-county, Kisumu County, River Nyando in Kano Plains, which is located within this basin, is notorious for bursting its banks during the rainy season from March to May and September to October every year. During this season of perennial floods rains can assume deluge proportions within certain areas, such as the delta of the Nyando River, where the equivalent of two months' rainfall can be experienced within a 24-h period. Kano Plains which is located in Western Kenya (Fig. 1) is however characterized by broken low ridges and river valleys further extends deep into Kisumu East sub-county in Kisumu County (Ocholla 2010). This region of land formation in the lower course of Nyando River covers approximately $50 \%$ of the Nyando sub-county (Ongor 2007). The Floods, from the spills of river Nyando and small rivers such as Ombeyi, Awach Kano, Nyaidho, Ang'wecha and Kibos in Kano Plains, occur annually and the cost of moving people from one area to another and of other relief efforts is quite high. During such events, public institutions have to be closed down. By and large, most floods in Kenya occur immediately after the droughts causing devastating impacts (Ocholla 2010). The community living in Kano Plains, Kisumu County, Kenya, views their perception and risk to flooding as being comparatively low (Nyakundi et al. 2010). In as much as River Nyando and other rivers in Kenya have a history of flooding during the long rains, no meaningful flood control measures have been taken (Otiende 2009). Kenya is still at the formation phase in the development of strategies to cope with floods. It is still in the process of harnessing the benefits from the rivers, the floods and the floodplains by farming the fertile soils, irrigation and fishing (Bakibinga-Ibembe et al. 2011). Though literature search in Kenya and the world reveals that mitigation studies and work are continuously going on towards addressing the flood problem in the flood prone areas in Kenya, concentration of population around flood-prone areas and flood-induced damages are continuously 


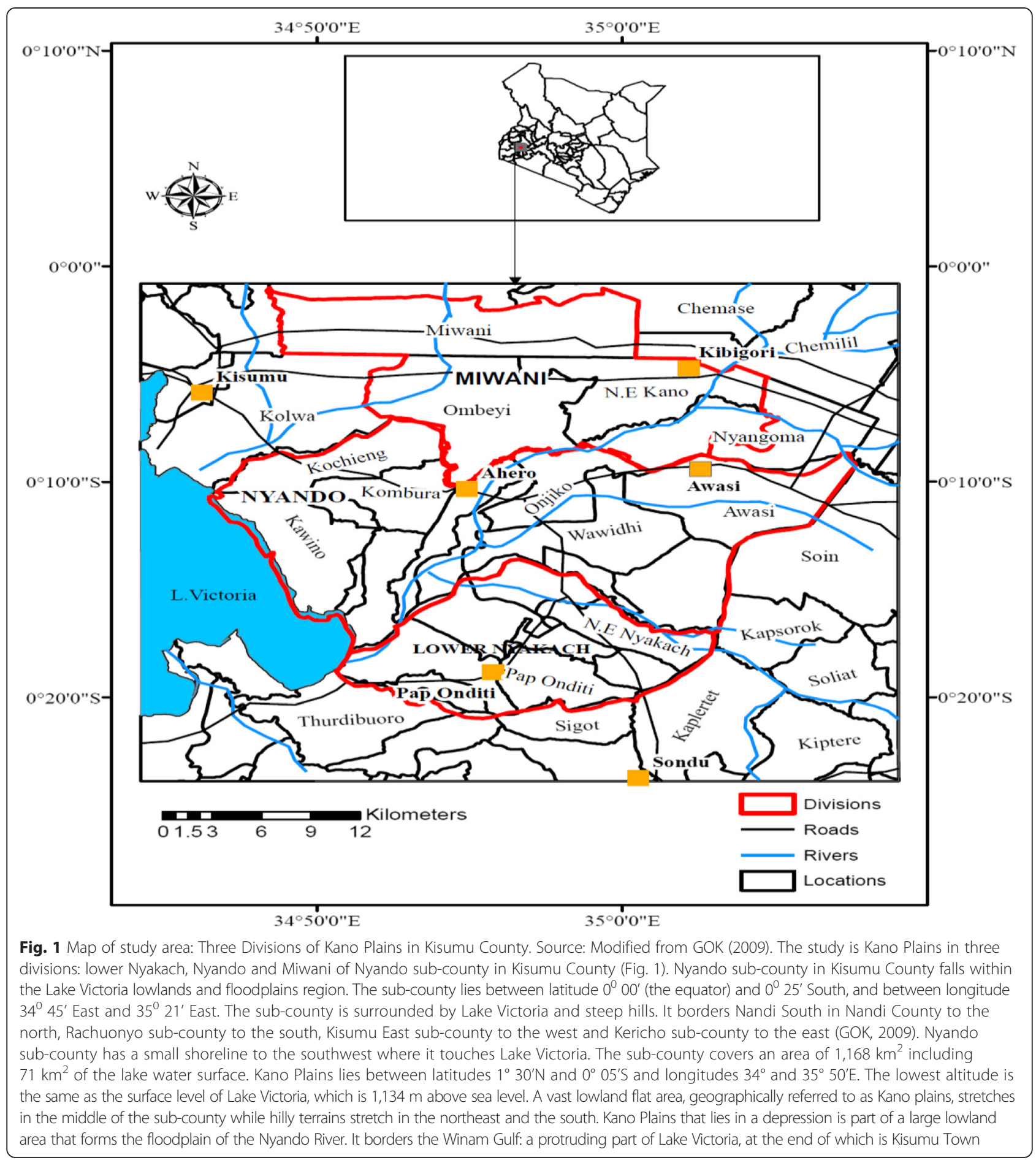

increasing (Masibayi 2011). According to Nyando District Development Plan 2008-2012: Kenya Vision 2030 Towards a globally competitive and prosperous Kenya by Ministry of Planning and National Development GOK (2009), Miwani and Nyando divisions have the highest count of poor people. Poor agricultural technology, lack of proper storage, frequent floods, low wages, unemployment, lack of markets for the rice, the impact of HIV and AIDS (with 29.4 \% infection rate) and low commodity prices are some of the factors that aggravate poverty in the areas. According to Kenya National Bureau of Statistics-Keeping you informed Economic survey 2014 by Ministry of Planning and National Development GOK (2014), the poverty gap (how far off individuals are 
from poverty line) of Kisumu County is $9.0 \%$ against a total population of 951,587 . This means therefore that it is not easy to convince a poor person to listen to information about and take actions to minimize losses as a result of flooding.

Thurairajah et al. (2010) assert that many nations carry out actions that are related to elimination or reduction of the probability of the occurrence or reduction of the effects from unavoidable disasters, the lack of incorporation of the local conditions and vulnerabilities act as a hindrance to their success. This bespeaks the need to include local knowledge and skills from specific communities in disaster prevention activities.

MacLeod (2003) recommends that involving community members, not only increases the likelihood of increased action by communities to help mitigate flood disaster, but also brings communities together to address flood issues cooperatively. In the event of a flood, cooperative actions among communities can lead to a great probability of decreased damage, deaths and economic devastation in the affected communities.

Opondo (2013) findings reveal that many of the coping measures at the household level such as selling of property and reliance on support from public and private agencies, and temporary relocation and migration, are erosive as they have negative long-term effects on household livelihood sustainability. He recommends that interventions such as construction of dams and dykes could benefit from the wealth of traditional knowledge accumulated over the years by the local communities.

Nyakundi et al. (2010) and Shen (2010)) findings on flood risk perception studies in rural and urban settings respectively conclude that perception of risk is influenced by several variables, most notably past experience of major floods and having survived them. There exists an excess of confidence in structural measures which has made the residents underestimate the impact of accumulating risk and biased the decision-making process.

Parker, Priest, and Tapsell (2009) correlate socioeconomic variables to flood warning response. For example, tenure or ownership usually influence householders' and business owners' response. Apart from the patchiness in geographical coverage, they further cite age, gender, education level and socio-psychological processes as variables affecting flood warning response.

In 2010 flash floods that hit Lower Nyakach and Nyando divisions badly, Kenya Red Cross Society (KRCS) advance team from Nyando branch and the Provincial administration conducted a rapid assessment and at the same time activated the sensitization campaigns for people to move to higher grounds for those at risk of the flash floods. The team, through the KRCS, distributed food and non-food items to the displaced families as an emergency intervention. It is understood that emergency intervention by the KRCS encourages the inhabitants of the flood-prone Kano Plains to rely on hand-outs instead of preparing to be resilient to the flooding events.

Denga (1990) affirms that people continued to occupy the flood plain as all or most of their economic activities were centred there - including fishing, irrigated rice cultivation and other cultivation. Other factors which affect individual adjustment include income levels, hazard exposure and levels of education. It is assumed that the flood-affected people already know how to mitigate flooding effects; but the benefits of flood-prone Kano plains outweighs the negative effects. Therefore, knowledge of flooding events and attitude change that influence appropriate practice(s) is paramount if mitigation measures can be sustained. The study thus, explores the socio-economic characteristics of the community that determine uptake of precautionary measures to mitigate flood disaster. The socio-economic characteristics explored here are education level of household, marital status, household composition; proximity to River Nyando, income level and occupation, and social network type one belonged to.

\section{Methods}

This study was intended to examine the socio-economic characteristics of the community that determine the ability to uptake precautionary measures to mitigate floods in Kano Plains.

The study also explored the precautionary measures the community undertook after learning about the threat of floods. The measures included removing family, going to evacuation centres, remove household items, alert neighbour, put domestic animals to safety and evacuate to higher grounds among other measures.

\section{Data collection}

The research findings in this paper were obtained from a household cross-sectional survey through use of questionnaires conducted among a predetermined sample of 384 households spread across three divisions: Miwani, Nyando and Lower Nyakach of Kano Plains, Nyando sub-county (Fig. 1). The divisions were selected purposively based on geographical location (nearness to River Nyando that spills its waters) and flood experience. Multi-stage random sampling and proportionate sampling were used to select the clusters in the three divisions. Through purposive sampling, the interview schedule mainly focused on the heads of the households (either male of female). The respondents consisted of $53.4 \%$ (203) males and $46.6 \%$ (181) females from 15 years and above. The mean age of the respondents was 39.3 years. Focus Group discussion was used to collect qualitative data from 6 village elders and 32 
participants from community-based organizations (2 women and 2 youth groups).

Purposive sampling was also used to select key informants who included officers from government offices (at the sub-county level): County Disaster Committee; schools, local administration, government ministries; NonGovernmental Organizations-NGOs (Kenya Red Cross, Victoria Institute of Research and Development (VIRED), Japan International Cooperation Agency (JICA); Faith Based Organizations (FBOs); and Community Based Organizations (CBOs)- youth and women groups with the richest source of information. Questionnaire instrument used in this study was adopted on the assumptions of Rea and Parker (2012) that contend that surveys using questionnaires are the most widely-used data-gathering technique in research and can be used to measure issues that are crucial to the management and development of human resources, such as behaviour, attitudes, beliefs, opinions, characteristics and expectations. Questions about marital status, the highest level of education attained, occupation, income level per month, ownership of household goods, flood experience, loss incurred as a result of last floods, closeness of main house to river Nyando that floods perennially, whether they worry about floods or not and social network type one belonged to were asked to ascertain the socio-economic characteristics of the community. A question on what precautionary measures the household undertook after learning about the threat of floods (14 statements) was asked and respondents were to check only the appropriate actions they undertook as summarized in Table 1.

The outcome of interest of the study was flood mitigation which was based on level of precautionary measures undertaken by households after getting warnings/education about flood mitigation. Fourteen (14) actions/measures were used to calculate the household score whereby, if the correct action was taken, the score was $=1$, otherwise, any wrong action was given $=0$ (Table 2$)$. The higher the score, the higher the uptake of precautionary measures, and vice versa. A cut off between 0 and 14 was used to classify the scores into high and low. A high uptake was a score from at least 7 and above. Below 7 was low score. A cut off of 7 points was arbitrarily selected as the mid-point between 0 and 14 which was the maximum point achieved by households. This resulted in a binary dependent variable of high and low as summarized in Table 2.

\section{Results and discussion}

The socio- economic characteristics that were assessed were marital status of the households, educational level, distance of main house to River Nyando, income level, occupation, household composition, dominant construction material of wall of main dwelling unit and social network type. The study analyzed the results among the respondents with low uptake of precautionary measures to mitigate floods as outlined in Table 3 and explained in the following sub- sections.

\section{Educational level}

The results of the highest level of education interrogated among those with low uptake showed that $68.2 \%$ (73) was secondary level, $66.7 \%$ (6) post-secondary, $66.2 \%$ (53) no education, and $54.2 \%$ (84) primary. A chi-square test conducted revealed that high level of uptake of precautionary measures was not dependent on education level of the households $(p=0.094)$ and dominant construction material of wall $(p=0.531)$, but on four factors: closeness of the main house to River Nyando $(p=0.007)$, level of income, occupation of household respondent, and household composition all were statistically significant $(p=<0.0001)$ as outlined in Table 3. The finding means that, by and large, the respondents were progressive in education but they were still far away from the higher education which is so important today to create a knowledge based society. Omungu (2014) concurs that the community lacks awareness on flood disaster.

Education is a powerful driver of development and one of the strongest instruments for improving wellbeing. So, in this study, when one takes precautionary measures, then you are concerned about your well-being and consequently, your personal development.

Table 1 Precautionary Measures undertaken by respondents

\begin{tabular}{|c|c|c|}
\hline \multirow[t]{2}{*}{ No } & \multirow[t]{2}{*}{ Question item } & 1. Yes 2. No \\
\hline & & $\begin{array}{l}\text { Action taken, If } \\
\text { 'Yes,' score }=1 \text { and } \\
\text { If 'No' score }=0\end{array}$ \\
\hline 1. & Move family to another location & \\
\hline 2. & Call evacuation centres & \\
\hline 3. & Call the police & \\
\hline 4. & Safeguard house & \\
\hline 5. & Remove household items & \\
\hline 6. & Alert the neighbour & \\
\hline 7. & Put domestic animals to safety & \\
\hline 8. & Put valuables to safety & \\
\hline 9. & Keeping belongings at the high places & \\
\hline 10. & Make trenches in front of the house & \\
\hline 11. & Store food grains & \\
\hline 12. & Make houses with wooden logs & \\
\hline 13. & Make small dams at the entrance of the house & \\
\hline 14. & Plant trees at the river banks & \\
\hline
\end{tabular}

Source: Field work (2014)

Fourteen (14) actions relating to the precautionary measures were used to calculate the household score whereby, if the correct action was taken, the score was $=1$, otherwise, any wrong action was given $=0$. The higher the score, the higher the uptake of precautionary measures, and vice versa 
Table 2 Frequency for Uptake Scores

\begin{tabular}{|c|c|c|c|}
\hline \multirow{6}{*}{ Low uptake } & Score & Frequency & Percent \\
\hline & 0.00 & 44 & 11.5 \\
\hline & 1.00 & 3 & .8 \\
\hline & 2.00 & 7 & 1.8 \\
\hline & 3.00 & 13 & 3.4 \\
\hline & 4.00 & 23 & 6.0 \\
\hline \multirow{11}{*}{ High Uptake } & 5.00 & 62 & 16.1 \\
\hline & 6.00 & 91 & 23.7 \\
\hline & 7.00 & 65 & 16.9 \\
\hline & 8.00 & 39 & 10.2 \\
\hline & 9.00 & 23 & 6.0 \\
\hline & 10.00 & 7 & 1.8 \\
\hline & 11.00 & 2 & .5 \\
\hline & 12.00 & 1 & .3 \\
\hline & 13.00 & 2 & .5 \\
\hline & 14.00 & 2 & .5 \\
\hline & Total & 384 & 100.0 \\
\hline
\end{tabular}

Source: Fieldwork (2014)

Gichere et al. (2013) affirm that Nyando had the highest percentage $(20.8 \%)$ of uneducated in the floodprone regions of Rarieda, Budalangi and Nyando). The low education level of the respondents in this study is a common feature of rural households in Kenya National Bureau of Statistics (KNBS) 2010). The finding on education level in this study means that education advocated for by Dufty (2009), and Hyogo Framework for Action (HFA) are lacking, and should therefore be a priority in this region because education plays a critical, and in some cases, only method to mitigate the impacts of natural hazards. A strategy to promote education in the rural setting should be embraced forthwith.

This finding supports Reynaud et al. (2013) that the socio-economic variables characterizing households play only a minor role in flood protective behaviours. Educational level is found not to be significant, similarly, household's income and age. However, they assert that flood experience is a significant driver of flood protective behaviours. In particular, being flooded results in a higher probability of moving to another area and, for farmers, in a higher number of self-protection strategies. Being evacuated increases floor elevation and the likelihood to move to another area. A traumatic experience such as being evacuated is shown to have an impact on some long-term household decisions such as the one to migrate to another area Reynaud et al. (2013. In this study, a flooding event is not a threat to initiate precautionary measures to mitigate the impact of the flood.

A Focus Group Discussion (FGD) with St. Rita women group to ascertain if education has prepared them enough to mitigate the effects of flooding paints a negative picture of those charged with the responsibility of disseminating flood information. They had this to say:

No, floods is with us, it is part of us. Even those who enlighten people on flood mitigation do not have the technical expertise: they have basic education on disaster management. So, there is nothing we'd say we have gained from them. We have always lived with floods.

This assertion means that the community is resigned to the status quo; come floods or no floods. So whether you are educated or not does not influence one's uptake of precautionary measures.

A number of other researchers find no association between education and preparedness behaviours (Lindell and Hwang 2008; Karanci et al. 2005). They assert that higher levels of education are associated only with preparedness activities related to obtaining knowledge and skills, such as first aid or fire control. Paul and Bhuiyan (2010) indicate that in Bangladesh, higher education levels are negatively associated with preparedness activities, suggesting that individuals with higher incomes typically live in newer housing designed to be earthquake-proof and therefore do not take as many preparedness actions. 
The finding on educational level in this study contradicts Brody, Kang and Bernhardt (2010). Among other socio-economic characteristics of the two groups, education was found to be a major driver of non-structural mitigation $(p=0.001)$. They argue that a more educated public may be more receptive to strategies that involve information dissemination, training, and voter-supported projects. They further ascertained that the education level of community residents also drives the implementation of nonstructural flood mitigation techniques since they are likely to be more aware of the long-term benefits of nonstructural approaches and the past failure of structural approaches.

These results have important implications for the modification of programmes for targeting sustainable behaviour change which is more likely to reduce the impact of future floods. It is important to note that educational level of this community does not necessarily result

Table 3 Socio-economic characteristics of households and association with uptake of precautionary measures

\begin{tabular}{|c|c|c|c|c|}
\hline Factors & Responses & $\begin{array}{l}\text { Low level of uptake } \\
n(\%)\end{array}$ & $\begin{array}{l}\text { High Level of uptake } \\
n(\%)\end{array}$ & $P$ value \\
\hline \multirow[t]{4}{*}{ Highest level of education } & None & $53(66.2)$ & $27(33.8)$ & 0.094 \\
\hline & Primary & $84(54.2)$ & $71(45.8)$ & \\
\hline & Secondary & $73(68.2)$ & $34(31.8)$ & \\
\hline & Post secondary & $6(66.7)$ & $3(33.3)$ & \\
\hline \multirow[t]{2}{*}{ Closeness of main house to River Nyando } & $2 \mathrm{Kms}$ and below & $226(65.5)$ & $119(34.5)$ & 0.007 \\
\hline & More than $2 \mathrm{Kms}$ & $17(43.6)$ & $22(56.4)$ & \\
\hline \multirow[t]{2}{*}{ Level of income } & None & 107(87.0) & 16(13.0) & $<0.0001$ \\
\hline & Some Income & $136(52.1)$ & 125(47.9) & \\
\hline \multirow[t]{6}{*}{ Marital status } & Single & $47(72.7)$ & $18(27.3)$ & 0.016 \\
\hline & Married & $87(36.9)$ & 149(63.1) & \\
\hline & Widowed & $30(47.9)$ & $35(52.1)$ & \\
\hline & Widower & 12(70.6) & $5(29.4)$ & \\
\hline & Divorced & 10(83.4) & $2(16.7)$ & \\
\hline & Separated & $1(20.0)$ & $4(80.0)$ & \\
\hline \multirow[t]{8}{*}{ Occupation } & Unemployed & $39(84.8)$ & $7(15.2)$ & $<0.0001$ \\
\hline & Farming & $89(54.9)$ & $73(45.1$ & \\
\hline & Trading & $49(54.4)$ & $41(45.6$ & \\
\hline & Artisan & $3(42.9)$ & $4(57.1)$ & \\
\hline & Wage employment & $36(78.3)$ & $10(21.7)$ & \\
\hline & Salaried employment & $6(85.7)$ & $1(14.3)$ & \\
\hline & Fishing & $3(50.0)$ & $3(50.0)$ & \\
\hline & Other (specify) & 18(90.0) & $2(10.0)$ & \\
\hline \multirow[t]{4}{*}{ Household composition } & Large family & 155(58.3) & $111(41.7)$ & $<0.0001$ \\
\hline & Single parent & $26(59.1)$ & $18(40.9)$ & \\
\hline & One person & $51(92.7)$ & $4(7.3)$ & \\
\hline & Other (specify) & $9(64.3)$ & $5(35.7)$ & \\
\hline \multirow[t]{4}{*}{ Social organization Type } & Social news services & $39(62.9)$ & $23(37.1)$ & $<0.0001$ \\
\hline & Location-based networking & $121(77.1)$ & $36(22.9)$ & \\
\hline & Community building services & $16(50.0)$ & $16(50.0)$ & \\
\hline & Other (specify) & $0(0.0)$ & $1(100.0)$ & \\
\hline \multirow[t]{2}{*}{ Dominant wall construction material } & Brick/stone (permanent) & $44(66.7)$ & $23(33.3)$ & 0.531 \\
\hline & Others (temporary/semi-permanent) & 199(62.6) & 119(37.4) & \\
\hline
\end{tabular}

Source: Fieldwork (2014)

The socio economic characteristics of the households were assessed to gauge their association with precautionary measures to mitigate floods. These characteristics were educational level of the households, distance of main house to River Nyando, income level, marital status, occupation, household composition, social network type and dominant construction material of wall of main dwelling unit. Those characteristics highly associated with uptake had a $p<0.0001$ 
in positive actions against flooding impacts. It is the actual behaviour change that needs to take place in the form of actions geared towards lessening the impact of flooding. So messages for flood - prone dwellers should be targeted to specific groups of people/diverse audiences bearing in mind age differences, gender and different levels of formal education. This is so because on regression model (Table 4), education level comes out as a significant predictor of uptake of precautionary measure $(p=0.0935)$, yet on its own, it is not. This therefore means that those with high education level are more likely to take appropriate actions to mitigate floods as opposed to those with low level of education. This study could borrow from Atkin and Freimuth (2001) who advocate for awareness messages that present relatively simple content that inform people what to do, specifies who should do it, or provides cues about when and where it should be done. Persuasive messages that appeal to community affected by flooding and build on existing values of the target audience or change beliefs about the likelihood of experiencing individual valued consequences are welcome. However, in this study, the most significant predictors of uptake of precautionary measures were stakeholder involvement $(p<0.0001)$; income level $(p<0.0001)$; marital status $(p=0.0251)$ and closeness of residence to river $(p=0.0342)$ as indicated in Table 4.

Asked how clearly they know what mitigation actions to adopt to be able to prepare for floods and respond to them effectively, of the 237 responses that were of low uptake, a large percentage $68.9 \%$ (142) indicated it was not clear, $62.9 \%$ (22) very clear, $56.4 \%$ (44) not clear at all, and $50.0 \%$ (29) was clear. A chi square test

Table 4 Binary logistic regression model for predictors of uptake of precautionary measures

\begin{tabular}{lccccc}
\hline Factors & \multirow{2}{*}{$\begin{array}{l}\text { Odds } \\
\text { Ratio } \\
\text { Estimates }\end{array}$} & \multicolumn{3}{c}{ 95\% confidence intervals } \\
\cline { 5 - 6 } \cline { 5 - 6 } & 0.718 & 0.537 & 0.96 & 0.0251 \\
\hline Marital status & 1.495 & 0.902 & 2.478 & 0.1185 \\
Have Ever Heard of flood & 3.412 & 1.977 & 5.891 & $<0.0001$ \\
Enough Action by Stakeholders & & & Upper & $P$ value \\
Construction of Wall & 0.849 & 0.647 & 1.115 & 0.2389 \\
Construction of Floor & 0.933 & 0.7 & 1.243 & 0.6357 \\
Closeness to river & 0.745 & 0.568 & 0.978 & 0.0342 \\
Highest Education Level & 1.24 & 0.964 & 1.594 & 0.0935 \\
Occupation & 1.04 & 0.881 & 1.227 & 0.6454 \\
Income level & 1.94 & 1.599 & 2.355 & $<0.0001$ \\
\hline Source: Finn & & & &
\end{tabular}

Source: Fieldwork (2014)

All variables of study put together, a binary logistic regression analysis was performed to identify the most significant predictors of uptake of precautionary measures to mitigate floods. Results show the most significant predictors as stakeholder involvement $(p<0.0001)$; income level $(p<0.0001)$; marital status $(p=0.0251)$ and closeness of residence to river Nyando $(p=0.0342)$ conducted to ascertain an association between knowledge clarity on what mitigation actions to take and uptake of precautionary measures reveal a significant association $(p=0.033)$. The respondents' answers were cross-tabulated with uptake as indicated in Table 5.

On attitude to flood mitigation education, one KII informant felt that:

Any flood education or flood mitigation campaigns that is geared towards helping the community cope with or control floods is not taken seriously because education is viewed as a hurdle to gaining the 'benefits' of flooding. To the vulnerable community, flooding is equal to relief supplies from the government/NGO: a kind of a cushion from hunger. They are only living for the now time. Permanent solutions to flooding is not in the community's interest. They feel floods should be there forever rather than lack of it.

This finding concurs with Mileti et al. (2004) who observed that there is a known psychology of public hazard education which explains how, why and what makes public education and communication about hazards work or fail. Perceived risk does not contribute directly to taking protective responses and informing people that they are at risk of flooding does not mean that they will respond to a flood warning even if they are at risk. They suggest that public flood communication and education is likely to work best when the materials and approaches used create uncertainty in people's minds, causing them to wonder about their environment and to question their safety in it.

Table $\mathbf{5}$ Knowledge clarity of mitigation actions and uptake of precautionary measures

\begin{tabular}{|c|c|c|c|c|c|}
\hline & Responses & $\begin{array}{l}\text { Low level } \\
\text { uptake n (\%) }\end{array}$ & $\begin{array}{l}\text { High level } \\
\text { uptake n (\%) }\end{array}$ & Total & $\begin{array}{l}P \\
\text { value }\end{array}$ \\
\hline \multirow[t]{5}{*}{$\begin{array}{l}\text { Knowledge } \\
\text { clarity }\end{array}$} & $\begin{array}{l}\text { Not clear } \\
\text { at all }\end{array}$ & $44(56.4)$ & $34(43.6)$ & $\begin{array}{l}100.0 \\
(78)\end{array}$ & 0.033 \\
\hline & Not clear & $142(68.9)$ & $64(31.1)$ & $\begin{array}{l}206 \\
(100.0)\end{array}$ & \\
\hline & Clear & $29(50.0)$ & $29(50.0)$ & $\begin{array}{l}58 \\
(100.0)\end{array}$ & \\
\hline & Very clear & $22(62.9)$ & $13(37.1)$ & $\begin{array}{l}35 \\
(100.0)\end{array}$ & \\
\hline & Total & $237(62.9)$ & $144(37.1)$ & $\begin{array}{l}377 \\
(100.0)\end{array}$ & \\
\hline
\end{tabular}

Source: Field work (2014)

Response of respondents on the question on 'how clearly they know what mitigation actions to adopt to be able to prepare for floods and respond to them effectively' was captured among 377 respondents. 237 (62.9\%) were of low uptake. A chi square test was conducted to ascertain an association between knowledge clarity on what mitigation actions to take and uptake of precautionary measures. Results reveal a significant association $(p=0.033)$ 
The Kenya Meteorological Department issued warning in September 2015 of El Niño with possible devastating effects. However, this came with a caveat that this may not be very significant: $80 \%$ possibility of El Niño in October 2015 but ruled out devastating effects like the 1997-98 rains. The overly cautious approach by the local weather men is a contrast statement released on September 1, 2015 by the United Nation's World Meteorological Organization (WMO) of which Kenya is a member. The WMO reported that $2015 \mathrm{El}$ Niño event will be the strongest since 1997-1998 and is potentially among the four strongest events since 1950 (Gathura 2015). Despite the contradictory messages on El Niño flood, some countries, especially in Asia and Latin America continued to prepare bearing in mind that the UN first issued El Niño alert in January 2014, and followed it with another one in June 2014.

It is evidenced Kenya continued to ignore this alert and after twenty-one (21) months, it dawned on her to start last-minute preparations in the very month the $\mathrm{El}$ Niño flood is likely to strike.

In this very month, October 2015, the state of flood disaster preparedness is still wanting. Last- minute budgets and impromptu desk committee meetings are going on in nearly all counties in the country. Every county is now doing last-minute preparation to mitigate the impact of anticipated El Niño floods which has already started in Mombasa, a coastal town and other areas. Reports from various counties indicate near lack of preparedness to mitigate the effects of floods. It is only now that vulnerable communities are being told of actions to take (Mabatuk 2015; Wachira 2015; Ngunjiri 2015).

According to Nzuma (2015), Kisumu County where Kano Plains is located has no fears of El Niño threat and the government expressed confidence that the county is prepared to tackle El Niño. It has desilted $250 \mathrm{~km}$ of waterways in a bid to increase flow of water once the rains begin. In addition it has intensified activities around opening of drainages and building of dykes along river banks, and planning to purchase emergency supplies (foodstuff, bedding, medicine, and clothes). It is reported that there are no fears, but on the ground, there are. The question one asks is: How long will it take to construct a dyke that withstands floods? What materials will be used? This is anybody's guess.

In short, county emergency and mitigation measures for the anticipated El Niño flood in October 2015 include and not limited to setting aside finances in millions of shillings towards mitigation measures, establishing emergency/risk management teams, stock piling, vaccination of livestock against disease outbreaks, planning to build dams, upgrading drainage systems, unclog blocked drainages and sewerage systems, flood hotspot mapping, shrub clearing, conducting public awareness campaigns on how to cope, warnings issued, relocating to safer grounds, designating camping centres, and alternative farming methods advised. All these are supposed to be done before the rains begin.

The above information of activities to be carried out explain the magnitude of flood threat in Kenya which is now a national issue more than ever before in the history of Kenya. The preparations underway are best explained by Chaos Theory in disaster management. According to Kiel (1994), disasters and emergency situations epitomize non-linearity of human events and designing response structures for disaster events is a difficult task, particularly when public resources are low. Where a disaster will occur is often unpredictable, or the way it will progress is unknown. A disaster response structure is 'emergent' because it did not exist at the time prior to the disaster. It involves the birth of new units or restructuring of old ones at the work group, organizational, community, or regional level that are more or less adaptive to a particular circumstance within the disaster. In recognition of non-linearity in human and organizational systems, Kiel (1994) lauds functionality of disorder and instability. Echoes of disorder and instability is evidenced in the last-minute preparations Kenyans are going through before the anticipated more than $125 \%$ 'above normal' rains Kenya gets during normal season

A discussion with a representative from NIB reveals that majority of the community do not move to higher grounds though some have lands at raised grounds. It is understood that they do not want to move until their flooded homes have been photographed and information about their circumstances is circulated to the public (media); and the Kenya Red Cross and/or donors bring relief supplies. It is emerging that reluctance to move to higher grounds is necessitated by the fact that 'moving to higher grounds will spoil how they 'eat.' VIRED also concurs that the community does not move to higher grounds except during emergency response when the flood waters have already destroyed their property and their safety is not guaranteed. With information to the public on several millions of shillings set aside for flood victims; it is unlikely to spot preparations to mitigate floods in the area this season.

This finding paints a pathetic picture of a community that has resolved to wholly depend on the government for relief supplies for as long as the government will stretch out its hands to provide for them; not that they cannot prepare to mitigate floods; but there are free hand-outs for the community. Flood time is 'harvest' time as revealed by a KII with one assistant chief. He says: 
The people here are resigned to the status quo. Floods is part of our life. Floods menace is a routine; nothing to cause alarm. Education does not bring food relief. But the moment they get wind of some relief supplies being distributed, then the turn out will be very high.

The assistant chief felt that flood education can only succeed if there is motivation to listen by informing the community that there would be relief distribution. How do we change this attitude?

The implication of this finding is that the households do not perceive any risk to flooding, and therefore no threat to their life. Even the village administrators feel flood education cannot succeed unless there is some token distributed to the households. This means that the community is so dependent on relief so much so that they do not see the need for investing in long-term flood mitigation measures such as education which is a lifelong process and that gives them knowledge on flooding. No wonder $76.82 \%$ (295) anticipated help from stakeholders as opposed to $19.53 \%$ (75) who did not; and a meagre $3.63 \%$ (14) who did not at all. In as much as it is the duty of the government to protect its citizens from disasters according to the Kenya National Draft Disaster Policy (GOK, 2011), an individual's coping skills are crucial since it is the individual/community that is the first responder to disasters.

The participant continues:

Ndalo ma pi omuom Nyando opong' to dhano ong'ee ni chiemo nitie kendo jotel oyudo gi piny nono. Sechegi emakata ne inindo kech to ing'eyo ni ibiro chiemo. Ibiro yudo onget, yedhe gi chiemo. Koro puonj nono ok jogidwa nikech floods gi ng'iyo go.'

Translated into English: ' the community knows that floods is a recipe for leaders to get free donations such as blankets, medicine and foodstuffs and that educating the community on how to mitigate the floods with bare hands is bound to backfire.'

The study acknowledges that motivation is the inner drive that propels human beings towards attaining a desired goal even if it is a short-term goal. Reliance on relief must be fought vigorously as it is a recipe for more disasters as identified in this study: the goal of the community is a short time physical satisfaction. Their perspectives and understanding of flooding is equated with filling the stomach as individual desired goals outweigh the risk of a disaster

\section{Marital status of respondents}

Of the sampled three hundred and eighty four (384) respondents, $61.5 \%$ (236) were married, $17.2 \%$ (66) single,
$16.9 \%$ (65) widowed, $3.1 \%$ (12) divorced, and $1.3 \%$ (5) separated (Fig. 2).

Of those with low uptake of precautionary measures, $83.4 \%$ (10) are divorced; $72.7 \%$ (48) single; $70.6 \%$ (12) widowers, $47.9 \%$ (23) widowed; $36.9 \%$ (87) married and $20.9 \%$ (1) separated (Table 3). Of the married category, only $36.9 \%$ (87) do not take precautionary measures. The findings indicate a significant relationship between marital status and uptake of precautionary measures to mitigate floods $(p=0.016)$. It is inferred that the households that have families have huge responsibilities of taking care of other people, other household members (for example, children), or even property in such circumstances as during disasters, while the single or separated or divorced, may not see the need to take precautionary measures because they do not have any other person other than themselves to care about and may develop 'I don't care attitude' and feel freer to do as they please. Thus, issues of individual well-being are only determined by an individual.

Further, logistic regression analysis to establish the strength of the relationship indicate that marital status of the households is still a significant predictor $(p=0.025)$. Besides marital status, the study also established that cultural ties have a huge bearing on uptake of precautionary measures, especially among widows. In Kore-Kasao, Ombeyi location (Miwani division), a widow was bound by cultural ties to bury her husband during the raging floods of May 2013. Burying the husband meant she had to stay in the flooded homestead for the whole period of mourning that takes several days. She could not leave her flooded homestead to the nearest evacuation centre because she was still mourning her husband. They explained that she had 'chola.' This meant that she was not allowed to go out and sleep anywhere be it in another homestead, neighbour's house, or even at the evacuation centre before being inherited by another husband/man since she still had 'chola': dirt from the dead husband's spirits. If the widow were still of child-bearing age, she needed a man to 'cleanse' the dirt through sexual intercourse. It was established that inheritance involved unprotected sexual intercourse between the widow and the appointed inheritor. Unless and until she was inherited, then she would not spend a night outside her home, flood disaster notwithstanding. Owuor (2007) concurs that the Luo community put a lot of pressure on women to be inherited, failure to which they could not go into people's homes. This finding means that even during disasters, it is not possible to divorce a people's culture for the sake of safety. No wonder, the Kenya National Draft Disaster Policy (KNDP) by Ministry of State for Special Programmes emphasizes the principles to guide effective disaster management to incorporate among others, respect for culture and customs of those affected during provision of disaster 


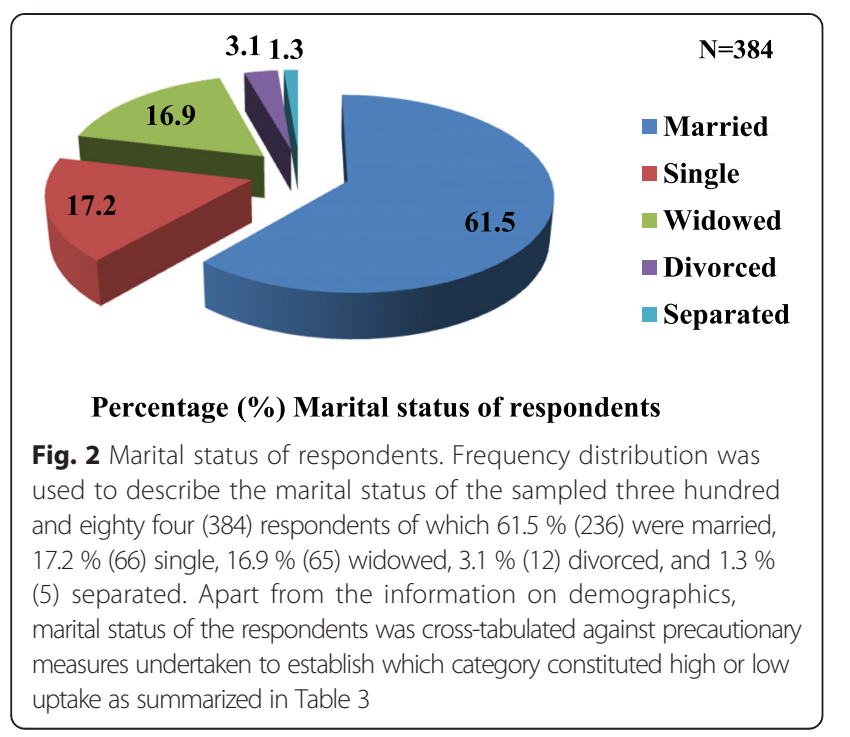

assistance (GOK 2011). It should be understood that culture and beliefs, for example, or simple fatalism, enable people to live with risks and make sense of their lives in dangerous places. Sometimes, though, unequal power relations are also part of culture, and those who have little influence must inevitably cope with threatening environments (World Disaster Report 2014). In this context, the findings of this study challenge the draft policy. Though the policy also aims to strengthen the resilience of vulnerable groups to cope with potential disasters, it is not clear how vulnerable groups such as women who are bound by outdated practices of a community can be empowered to be resilient during disasters because crude version of culture has no place for sustained argument in the face of disaster risk reduction.

\section{Household composition}

The research also revealed that household size of the sampled population comprised $70.3 \%$ (270) large family, $14.3 \%$ (55) one person household, $11.5 \%$ (44) single parent and $3.9 \%$ (15) 'other' to mean just staying together (Fig. 3).

The number of people living in the same house/home was found to be large. KNBS (2010) explains that the size of the household is associated with the welfare of the household. Households headed by women are, for example, typically poorer than households headed by men and that rural households are larger on average (4.6 persons) than are urban households (3.1 persons). Economic resources are often more limited in large households than in small households. Thus, where cost of preventive actions outweigh the needs of the household, it is only logical to solve the immediate domestic needs than preventive actions to mitigate floods.

\section{Closeness of main house to River Nyando}

To establish if closeness of the main house to river Nyando had any influence on precautionary measures, a chi-square test conducted reveals that closeness to River Nyando was significantly associated with uptake of precautionary measures $(p=0.007)$ (Table 3$)$. Of those with low uptake, majority $65.5 \%$ (226) lived within $2 \mathrm{kms}$ of the river compared to $43.6 \%$ (17) who lived further away from the river that floods. It is clear from these findings that despite having experienced floods before, those who live within $2 \mathrm{Kms}$ of the river know they are at risk of flooding but expect to be protected and rely on relief distribution from the government and nongovernmental organizations like KRCS. They are therefore unprepared to respond appropriately and effectively to flood warnings and sensitizations as opposed to those who live further away; at least $3 \mathrm{kms}$ away as predicted in the regression analysis $(p=0.0342)$ (Table 4$)$.

A KII with chiefs to find out if it was necessary, after community sensitization, to take up precautionary measures to cope with floods reveals:

The government must bring relief for them to dig channels or build dykes near their houses. There was a government programme known as 'food for work' that was meant for channelization of the River Nyando waters but it died ages back when some $\mathrm{CBOs}$ hijacked the programme and got tenders to do the job which was not in tandem with the original objectives. So nobody wants to prepare for floods!' Development funds such as cess for opening clogged rivers are non-existent. Preparation is not easy if there is no money.

The irony of the statement is that the community affected by flooding does not seem to see that it is the victim of flooding before the government comes in and should therefore prepare to mitigate the impacts. There is an attempt by the vulnerable community of Kano

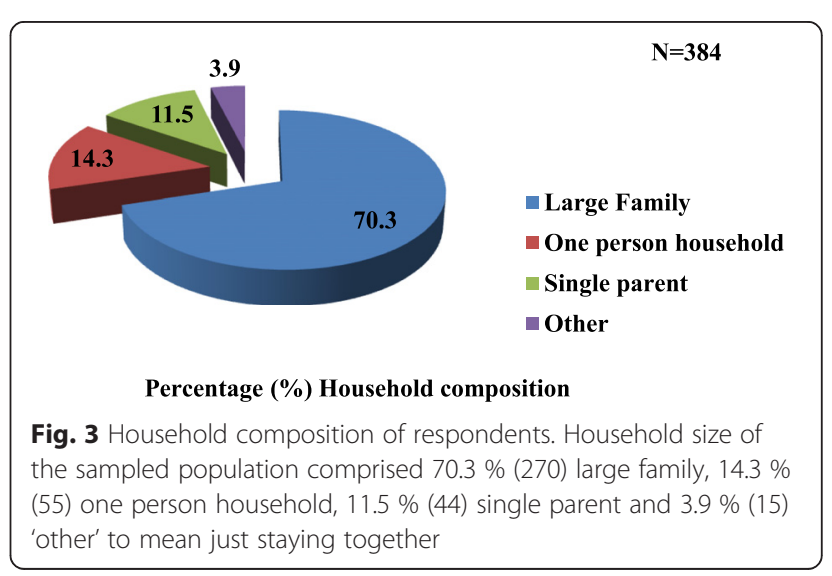


Plains to assume that if it prepares for floods; it is doing it for the government yet as an individual, one may be impacted by a given flood event in several ways: lose life and property, disease outbreak, movement curtailed and many more.

The famous news in Kenya on flood impact on households was publicized on television stations in May 2013 after River Nyando burst its banks and caused massive destruction in part of this study area: Wawidhi location, Nyando division where an earthen dyke that could not withstand the moving flood water gave way and caused flooding in a woman's house. The victim cried to the government in broken Swahili language to help her during the floods:

'serkal, saidia. Ata vitoto vime enda. Si jui bwana ame enda wapi'

Translated into English:

'Government, help. Even the children have gone. I

don't know where my husband is.'

A picture of a fast- moving flood water with utensils and chicken and the victim trying to clutch onto the only property she saw on site still hangs in many minds. It was learnt that her children had been sheltered by sugar plantation behind her but she couldn't see them. Much to the surprise of many, instead of being sympathised with, people ended up laughing at the broken Swahili and therefore neutralizing the magnitude of damage the flood event had brought with it. The tragic-comedy incident on a disaster such as floods shows that the community handles disaster impacts casually whereas, it is important to note that as an individual, you carry the burden of the impacts of flooding before the government can come in.

To find out if there are any challenges faced at the evacuation centres, attitude to preparation for floods to mitigate its impacts is also revealed in a KII with the in-charge of one faith-based organization where relief supplies is distributed during floods:

There are no major challenges once they have been accommodated except I have not followed-up on the goings-on in the parish during flooding as everything is taken care of by the Kenya Red Cross. However, the church has talked to community affected by flooding to look for alternative settlement but they will hear none of that. They seem not to care. How do you put up a very good house in a flood zone, lose you certificates and you travel all the way from Ombaka location which costs you Kshs 150 (one hundred and fifty shillings) to the evacuation centre for relief: a meal from the Kenya Red Cross and the government? The losses do not matter much to them. So long as the stomach is full with free food, they are okay. In my opinion, this is a painful thing. I have talked at burials about reliance on relief, but it seems I am opening an old wound. It is best I do not talk about it.

The study gathered that the reliance on relief is pegged on the history of the area. There have been many nongovernmental organizations in the area such as World Vision, DANIDA, the Kenya Red cross, OCHA, Child Fund and WASH. These organizations originally received direct funding from the European Union. The European Union pulled out three years ago. The community has relied on relief for ages from these organizations and it is high time vigorous/civic education be carried out to sensitize them about floods and the need for their own actions to mitigate the effects of flooding.

It is unknown to the government of Kenya that it has created a dependency syndrome in the country and among the flood vulnerable community; what with the information in the press about the amount of money it has set aside to mitigate the impact of rains. Gitonga (2015) reports that disaster agency says Shs. 16 billion is needed to mitigate impact of rains while the state has already set aside Shs. 5 billion. County governments were to contribute Shs. 6 to the exercise while the government tops up the balance. What is unknown is when will the preparations be done when the rains have already begun? What will happen to the money that is being dispatched to counties at this eleventh hour? A known fact to the community and the public at large is that money has been dispatched to their counties for relief supplies whether they prepare for floods or not.

It was also gathered that the community that lives opposite the Ahero Catholic Church was advised on how to build structures near the water area as they are only $40 \mathrm{~m}$ away from River Nyando. Canals were dug along the road in preparation for next floods. The study has gathered that the canals were refilled with soil and stalls/kiosks have already been reerected on the drainage line yet the long drought that has been witnessed in the area for the last three months is a sign that there is going to be weather extremes, i.e. flooding any time during the long rains in 2015.

Closeness of the main dwelling house to a river that overflows its banks helps determine the flood risk to one's home or business. Yande (2009) argues that human populations worldwide are vulnerable to natural disasters reveals various underlying causes of vulnerability. He concludes that the proximity to the floodprone area $(57 \%)$ and residing in flood prone area and poverty $(18 \%)$ were the main underlying causes of vulnerability by the Sikaunzwe community. 
He recommends that government and key stakeholders should engage communities in order for them to move permanently to higher grounds as they have expressed a willingness to relocate. Relocating should go with the provision of all the necessary socio-amenities such as schools, hospitals, infrastructure, water and agriculture support for a period of three (3) years to enable the households to settle. This means that certain conditions such as geographical location or people's income level can affect the degree to which natural disasters impact people's homes and livelihoods.

There is however mixed evidence that personal experience affects responses to hazards especially if you stare the hazard on the face. Some studies indicate that this is due to its effect on risk perception but there is also evidence of an effect that is independent of risk perception. In addition, there is conflicting evidence regarding the correlations of hazard proximity with hazard adjustment. Finally, there is evidence that people's adoption of hazard adjustments is related to the perceived attributes of those adjustments such as efficacy, utility for other purposes, financial cost, knowledge and skill requirements, time and effort requirements and required social cooperation (Lindell and Hwang 2008). In this study, proximity to hazard does not influence response. Currently in Kenya, flooding occurs in places they are rarely experienced. For example in Nairobi County, Kenya, the oncoming El Niño rains will mean a disruption of business activities and those commuting will experience endless hours in traffic jams (Achuka 2015). Despite flood warning alerts being issued by the meteorological department and the county Governor, the slum dwellers in Kibera say they are used to the rains and they are aware of the impending danger the destruction the rains will bring, but they can't move anywhere. One resident of the Kibera slum comments:

'We can't heed the warning since we have nowhere else to go. If I leave this house, it will be occupied by someone else and getting a house is difficult in Kibera. I would rather endure long nights of draining water than evacuate to another place.'

While you cannot improve distance of household locations and what people do, this study suggests that actual behaviour change does not require education, nor professional training, but rather, one's own initiative to carry out actions that cushion one against the negative impacts of flooding. This explains why some respondents who reside near the river have since relocated to places such as Onjiko, which is slightly a higher ground as a way of mitigating the effect of floods. Stakeholders should therefore emphasize specific messages targeted to residents who live close to the river because there is the risk to flooding for those who live in close proximity to river Nyando. If flooding is not taken care of, many inhabitants and homes will be submerged as the disaster is spreading rapidly, especially with the climate change impacts. The National Disaster Operations Centre has warned that the expected rains will be above normal$125 \%$ more than Kenya gets during normal season, and such high amounts of rain will result in flash floods, and high moisture levels promoting breeding of diseasecausing organisms.

\section{Income level and occupation}

Of those with low uptake of precautionary measures, a large percentage, $87.0 \%$ (107) had no income as opposed to $52.1 \%$ (136) that had some income. The level of income was significantly $(p<0.0001)$ associated with precautionary measures (Table 3 ). While you cannot improve the income of people, it is sometimes difficult to change the way people live (lifestyles). It should be understood that for the households with low or no income, only $13.0 \%$ (16) were in the category of high level uptake of precautionary measures. However, during an FGD with Odhus Women Group (Fig. 4), one participant who sought anonymity felt that if you admitted to having any income, then the government would not come to your assistance.

She lamented:

Yawa we awachnu adieri, ing'eni kaiwachoni in gi gimoro matin to ong'e ng'a mabiro winjo yuakni.

Koro afadhali aling' aling'a kata awachni aonge go.

Translated into English:

Let me tell you the truth, you know if you say you have money, nobody will come to your aid. So, I'd rather say I don't have anything to be able to be considered during relief distribution.

Some men also felt that they could not disclose their income. Asked about how much loss they incurred in terms of Kshs (Kenya shillings), the figure went up. Those who did not have any income were $34.1 \%$ (131), while $28.1 \%$ (108) lost large amounts of money. Nondisclosure of exact income by the respondents means that reliance on relief has created a dependency syndrome in the flood-affected community and therefore, this study acknowledges a flaw on the data on income of respondents.

Reynaud et al. (2013) stress that the socio-economic variables characterizing households play only a minor role in flood protective behaviours. Household's income is mainly found to be not significant, similarly to household age and level of education. Respondents' risk and time preferences are never significant. In this study, it is 


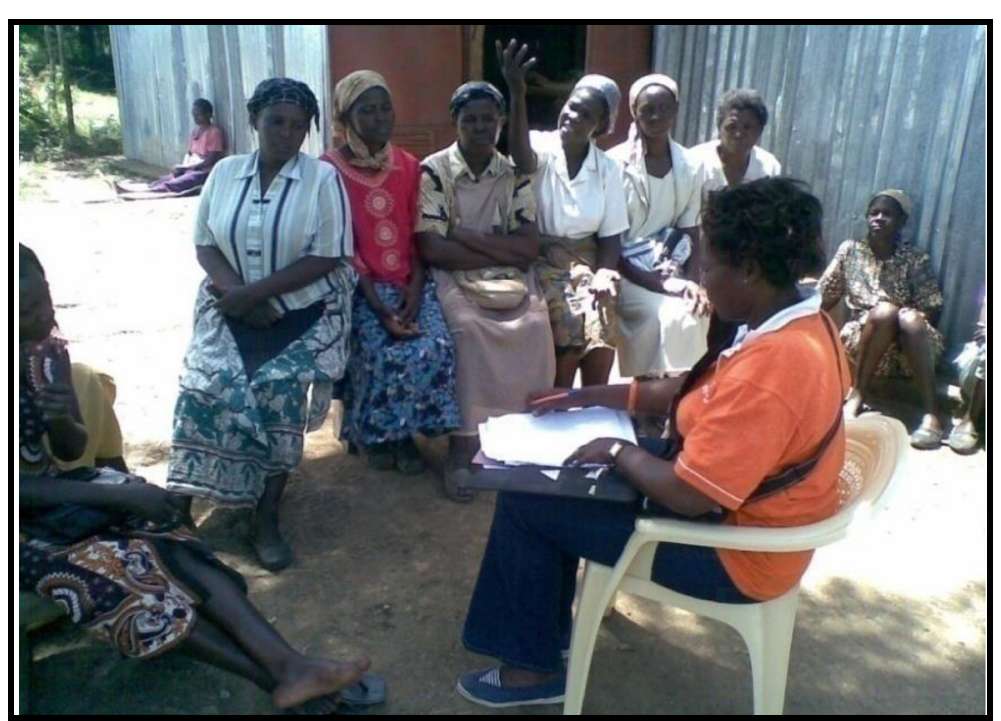

Fig. 4 The researcher (in orange) holding an FGD at Ahero Posho Mill with Odhus Women Group. The use of Focus Group Discussion (FGD) with the small group helped capture views representative of residents, especially women of Kano Plains on community sensitization for flood mitigation. It facilitated discussions with small groups from which community sensitization for flood mitigation issue was captured from community members' perspective. This helped explain in detail how the households regarded the flood menace

identified that poor income people, artisans, the unemployed and traders, and those who live within $2 \mathrm{Kms}$ of River Nyando do not do the right thing in terms of uptake of precautionary measures reason being they run businesses here and do not see why they should move away to other locations.

This finding concurs with Oppong (2011) that the Aboabo River flood-prone community continued to live in this area because as traders and artisans (carpenters), they operated these businesses and did not see any reason to move. In as much as they want to establish businesses, low uptake of precautionary measures was identified among the salaried employed $85.7 \%$ (6), unemployed $84.8 \%$ (39), wage employed $78.3 \%$ (3), farmers $54.9 \%$ (89), traders $54.4 \%$ (49), and artisan $42.9 \%$ (3) as indicated in Table 3. Denga (1990) confirms that continued occupancy of the floodplain is related to activities dependent on it and that the less educated and the poor are more reluctant to leave the flood plain and that those who live in the greater risk zones know and practice more flood damage control measures.

It was the opinion of all the disaster committee that socio-economic characteristics play a role in flood mitigation communication in that community's farming activities hamper them from evacuating holistically during flooding. They depend on land for livelihood. Moreover, on assessing if the respondents are concerned about flood mitigation information, out of 384 responses, a good percentage, $69.0 \%(265)$ said they were concerned while the remainder $31.0 \%$ (119) were not (Fig. 5). The respondents who said they were concerned had several reasons for such concern: floods are hazardous, dangerous if neglected and have terrible consequences, costly disaster, fatal and the fact that some of the respondents lost short period crops such as kales, spinach, and onions that they had cultivated along river banks in March 2013.

Some households explained that they were concerned about flood mitigation information to be able to adapt to future floods by putting in appropriate measures before, during and after flooding. For example at Kasiru village in Miwani division, individual women engage in preparedness activities such as looking for firewood and stocking enough of the same before the rainy season so they would be able to use the firewood when holed up at Kasiru Kudho AIC evacuation centre. They also assemble the three cooking stones somewhere near the evacuation centre because come rain or shine; they have families to cook for. This ensures that their families would not go hungry during floods.

In effect, they felt that concern about flood mitigation information would prepare them to face the disaster that is a perennial occurrence. Much concern about flood mitigation information of the households is based on the fear of the consequences of floods and having experienced the floods menace before. This means that the precautionary measures undertaken by households to a large extent depended on having experienced the negative impacts of the previous flood events and not being sure about impact of future floods. 
This finding concurs with Health Belief Model (HBM) explained by Rosenstock (1974) that when one perceives vulnerability (probability) and severity (consequence) of a threat, they evaluate the possible responses to the threat they face as well as their own ability to avert or avoid the risk to be able to respond appropriately. In this study, the households pay attention to flood mitigation information, for example, early warning, by attending chiefs' barazas and seminars, listening to the local radio stations for flood information, and consulting with friends and relatives on flood matters, especially on evacuation procedures. However, Parker et al. (2009) contradicts this finding. They affirm that perceived risk does not contribute directly to taking protective responses and informing people that they are at risk of flooding does not mean that they will respond to a flood warning, but rather, public flood communication and education is likely to work best when the materials and approaches used create uncertainty in people's minds, causing them to wonder about their environment and to question their safety in it. Giving people something to mull over and to discuss with family and friends sparks the motivation which is key to non-formal learning. Such an approach may increase the opportunity for nonformal learning amongst those living in flood risk communities and neighbourhoods.

A Key Informant Interview (KII) with the chiefs to further prod them on whether socio-economic characteristics do influence one's ability to uptake precautionary measures with or without sensitization, the responses of the participants were captured below:

Yes, it does affect the ability to uptake precautionary measures because the literacy level of the community is low. Even after education, one would secretly ask after the facilitator has gone:

En ni nowacho ang'o? Translated into English: 'What was he/she saying yet the participant was present throughout the session. Probably, they were just listening to the sound of words. With low literacy achievement, it is not possible to penetrate the minds of the participants.

Asked whether they thought it was necessary, after community sensitization, to take up precautionary measures to cope with floods, they responded:

The government must bring relief for them to dig channels or build dykes near their houses. There was a government programme known as 'food for work' that was meant for channelization of the River Nyando waters but it died ages back when some CBOs hijacked the programme and got

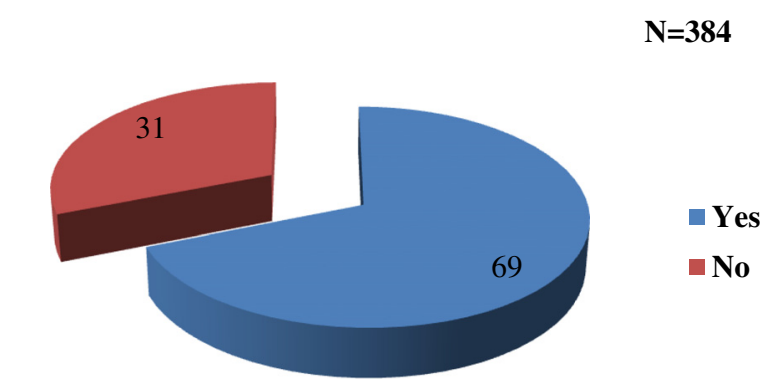

Percentage (\%) respondents' concern about flooding

Fig. 5 Respondents' concern for flood mitigation. Respondents' concern for flood mitigation was interrogated among the population sample of 384 , and the results reveal that a good percentage, $69.0 \%$ (265) was concerned while the remainder $31.0 \%$ (119) were not

tenders to do the job which was not in tandem with the original objectives. So nobody wants to prepare for floods!' Development funds such as cess for opening clogged rivers are non-existent. Preparation is not easy.

Reliance on the government to offer relief before a disaster strikes is an expression of dependency syndrome in Kenya in flood - prone areas (Nyakundi et al. 2010). When flood victims call upon the government to come to their aid to offer relief even after a warning alert has been issued, four conclusions can be drawn. First, the government's priority is response and not preparation and mitigation. Second, there is public apathy to warning. Third, warning might not have been issued in real time to elicit appropriate responses and lastly, those at risk do not understand their level of risk and if they did, it does not enhance taking appropriate measures to mitigate flood events.

A respondent at Ahero Catholic Parish concurs that many people prefer to be offered accommodation at the parish during flooding. The preference is because of relief. The study gathered that the reliance on relief is pegged on the history of the area. There have been many non-governmental organizations in the area such as World Vision, Danish International Development Agency (DANIDA), the Kenya Red cross, OCHA, Child Fund and WASH. These organizations originally received direct funding from the European Union. The European Union pulled out three years ago. The community has relied on relief for ages from these organizations and it is high time vigorous/ civic education be carried out to sensitize them about floods and the need for their own actions to mitigate the effects of flooding.

Reliance on relief is also revealed in the words of one key informant interviewee, a chief from Kang'o village. He says: 
Floods affect men more than women because:

Men have greater responsibilities than women: they are the ones who build houses that are swept away by floods. In the event of destructive flooding, they must look for timber or any material to start afresh or do repairs, rice fields swept away, they have to find out how to sustain the family that was dependent on rice growing as a source of livelihood. If secondary disasters occur such as air and waterborne diseases, it is the man who takes the family to the hospital, and he must look for money in all cases to sustain the family. Sometimes the wife runs away and comes back after the floods have subsided (way of coping!).

Because the males feel they have a lot to do for the family, and thus more affected, any assistance should be directed to the males.

In order to determine the precautionary measures undertaken by residents after flood mitigation education, a cross tabulation was performed between the measures and residents of the respondents and the results are summarized in Table 6.

The measure that ranked top was to put domestic animals to safety $77.6 \%$ (298). This was closely followed by alerting the neighbour $74.7 \%$ (267); then keeping belongings at high places $68.5 \%$ (263); making trenches in front of the house and storing food grains each at $55.5 \%$ (213); contact relatives $51.0 \%$ (196); household moving to another location $41.1 \%$ (159); call evacuation centres $35.4 \%$ (136), safeguard house $35.2 \%$ (135) and lastly call the police $20.8 \%$ (80). A chi-square conducted revealed that some precautionary measures undertaken such as putting valuables to safety, calling the police, contacting relatives, alerting the neighbour, storing food grain, putting domestic animals to safety and keeping belongings at high places were significantly associated with residence of the respondents $(p=0.000)$ as outlined in Table 6 .

Moving the family to another location was not dependent on the residence of the respondents $(p=0.463)$. Some of the respondents felt these activities were costly as they do it year in year out.

On further prodding on flood preparedness, the study found out that in as much as the community is predicting heavy flooding when the long rains begin in March 2015 , there is little or no preparedness to mitigate the effect of flooding. The chief says:

There is no preparedness, but we know this time it will flood heavily. The school will be used as an evacuation centre. The men fear going to evacuation

Table 6 Precautionary measures undertaken against residents of respondents

\begin{tabular}{|c|c|c|c|c|c|c|}
\hline Measures taken & Response & Miwani N(\%) & Nyando N(\%) & Lower Nyakach N(\%) & Total N (\%) & $P$-Value \\
\hline \multirow[t]{2}{*}{ Move family to another location } & Yes & $94(72.9 \%)$ & $64(43.8 \%)$ & $38(34.9 \%)$ & $196(51.0 \%)$ & 0.463 \\
\hline & No & $35(27.1 \%)$ & $82(56.2 \%)$ & $71(65.1 \%)$ & $188(49.0 \%)$ & \\
\hline \multirow[t]{2}{*}{ Put valuables to safety } & Yes & $98(76.0 \%)$ & $56(38.4 \%)$ & $59(54.1 \%)$ & $213(55.5 \%)$ & 0.000 \\
\hline & No & $31(24.0 \%)$ & $90(61.6 \%)$ & $50(45.9 \%)$ & $171(44.5 \%)$ & \\
\hline \multirow[t]{2}{*}{ Call the police } & Yes & $15(11.6 \%)$ & $53(36.3 \%)$ & $12(11.0 \%)$ & $80(20.8 \%)$ & 0.000 \\
\hline & No & $114(88.4 \%)$ & $93(63.7 \%)$ & $97(89.0 \%)$ & $304(79.2 \%)$ & \\
\hline \multirow[t]{2}{*}{ Contact relatives } & Yes & $38(29.5 \%)$ & $66(45.2 \%)$ & $31(28.4 \%)$ & 135(35.2 \%) & 0.005 \\
\hline & No & $91(70.5 \%)$ & $80(54.8 \%)$ & $78(71.6 \%)$ & $249(64.8 \%)$ & \\
\hline \multirow[t]{2}{*}{ Alert the neighbour } & Yes & $82(63.6 \%)$ & $109(74.7 \%)$ & 96(88.1\%) & $287(74.7 \%)$ & 0.000 \\
\hline & No & $47(36.4 \%)$ & $37(25.3 \%)$ & $13(11.9 \%)$ & $97(25.5 \%)$ & \\
\hline \multirow[t]{2}{*}{ Put domestic animals to safety } & Yes & $104(80.6 \%)$ & $100(68.5 \%)$ & $94(86.2 \%)$ & $298(77.6 \%)$ & 0.002 \\
\hline & No & $25(19.4 \%)$ & $46(31.5 \%)$ & $15(13.8 \%)$ & $86(22.4 \%)$ & \\
\hline \multirow[t]{2}{*}{ Keep belongings at high places } & Yes & 108(83.7 \%) & $69(47.3 \%)$ & $86(78.9 \%)$ & $263(68.5 \%)$ & 0.000 \\
\hline & No & $21(16.3 \%)$ & 77(52.7\%) & $16(14.7 \%)$ & $114(29.7 \%)$ & \\
\hline \multirow[t]{2}{*}{ Make trenches in front of house } & Yes & $98(76.0 \%)$ & $56(38.4 \%)$ & $59(54.1 \%)$ & $213(55.5 \%)$ & 0.000 \\
\hline & No & $31(24.0 \%)$ & $90(61.0 \%)$ & $50(45.9 \%)$ & $171(44.5 \%)$ & \\
\hline \multirow[t]{2}{*}{ Store food grains } & Yes & $79(61.2 \%)$ & $53(36.3 \%)$ & $81(74.3 \%)$ & $213(55.5 \%)$ & 0.000 \\
\hline & No & $50(38.8 \%)$ & $93(63.7 \%)$ & $28(25.7 \%)$ & $171(44.5 \%)$ & \\
\hline
\end{tabular}

Source: Field work (2014)

These were the precautionary measures undertaken by respondents after flood mitigation education. Cross- tabulation was performed to establish these measures in relation to where the respondents resided. Keep belongings at high places was ranked top in Miwani 108(83.7 \%), and alert neighbour at 96 (88.1 \%) and 109 (74.7 \%) in Lowwer Nyakach and Nandi division respectively. A chi-square conducted revealed that some precautionary measures undertaken such as putting valuables to safety, calling the police, contacting relatives, alerting the neighbour, storing food grains, putting domestic animals to safety and keeping belongings at high places were significantly associated with residence of the respondents $(p=0.000)$ 
camps because of their livestock. But those who remain hang their belongings at higher grounds in the house. Heavy furniture such as beds and sofa sets are just left in the house to be flooded. You cannot carry them to the camp. Likewise, you cannot move with the livestock.

The study established that livestock is so dear to this community as it is an important source of livelihood after rice. The community owns many herds of cattle (Fig. 6) and they cannot afford to see their source of livelihood being destroyed by the floods. They would rather die with their property than hear that their livestock have drowned in the floods while they were evacuated to the camps.

The many number of cows at the village is attributed to the wetlands that have grass and cyperus papyrus that the animals feed on throughout the year. However, the animals' hooves break the loosely compacted soil particles making it easier for erosion and flooding. This means that at certain times, routes become impassable for the community and they may suffer the threat of flooding. But this is nothing compared the fear of loss of their property (in this case, cows and land). Land being a source of production and livelihood is also one property that no one can let go of even if the flood event were extremely devastating. According to First Medium Term Plan (2008-2012), Kenya Vision 2030: A Globally Competitive and Prosperous Kenya by Ministry of Planning and National Development GOK (2008), a land use master plan is in place and should capture the livestock and wildlife censuses in the poor communities as well so that they are supported to improve their livestock breeds as well as being sensitized on driving livestock away to other regions, or selling them as a way of mitigating the effects of floods.
To get other opinion of the elders if they would relocate to another place if given land elsewhere as a precautionary measure and permanent solution to flooding, they responded in one voice:

No, we cannot leave our land. This is our grand fathers' land. In 1963, only a few youth left Kabonyo village to look for land elsewhere. The old would not go. This is our only source of livelihood. We grow rice here. It is our livelihood.

These sentiments are shared by a woman interviewee at Kasiru Kudho African Inland church evacuation centre (Fig. 7). Asked if she could move elsewhere if given land, she responded in the negative. To prod her further if she could go back to her original home in case of floods or what preparation she has in place, she says:

No, it is difficult to go elsewhere; I cannot. I have sons here, who will give them land where I was born? They'll be chased away from my home and asked to go back to their home. This is their known home. My sons are owners of this land. Your home is your home. So, we'll just wait for the floods to come and start anew. This has been the case.

She says her family will go to the nearest evacuation centre that carries up to 50 people. It is gathered that the JICA improved the sanitation facility/raised latrine (Fig. 7) while VIRED provided a water pump. The community incorporates both structural (raised floor) and non-structural measures to mitigate the impact of floods. However, the evacuation structure has open walls that make the structure very cold at night, allowing mosquitoes to move in freely at night when it has rained.

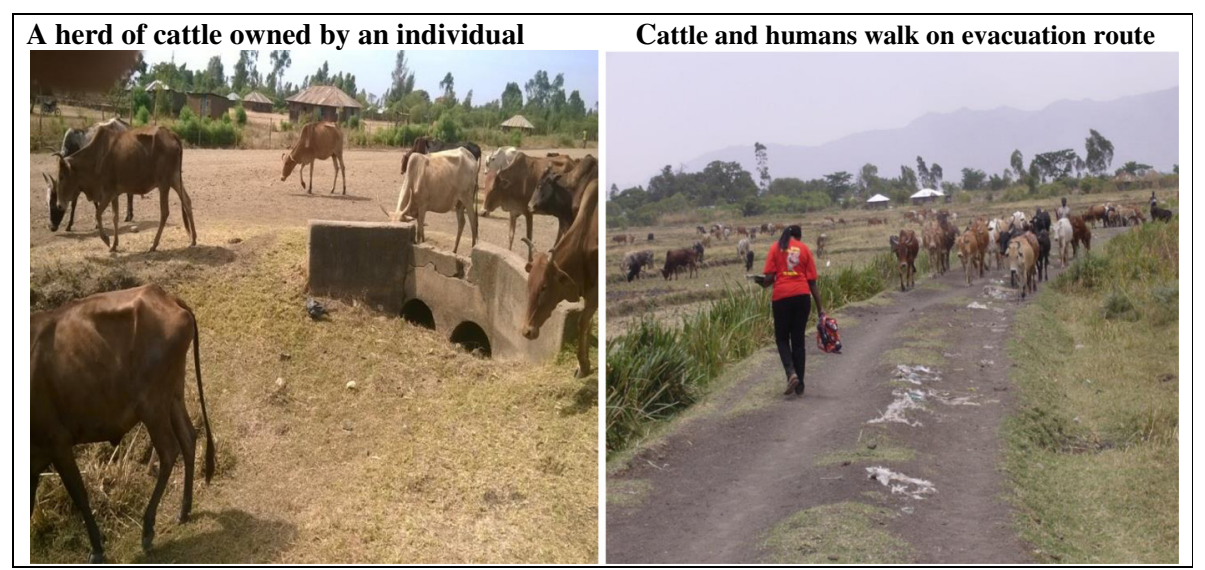

Fig. 6 Herds of cattle owned by individuals. Livestock is a source of livelihood in the community and accounts for over $50 \%$ of family income after rice. Livestock are owned by male respondents, and the more reason many elderly males do not leave flooded homesteads to evacuation camps 


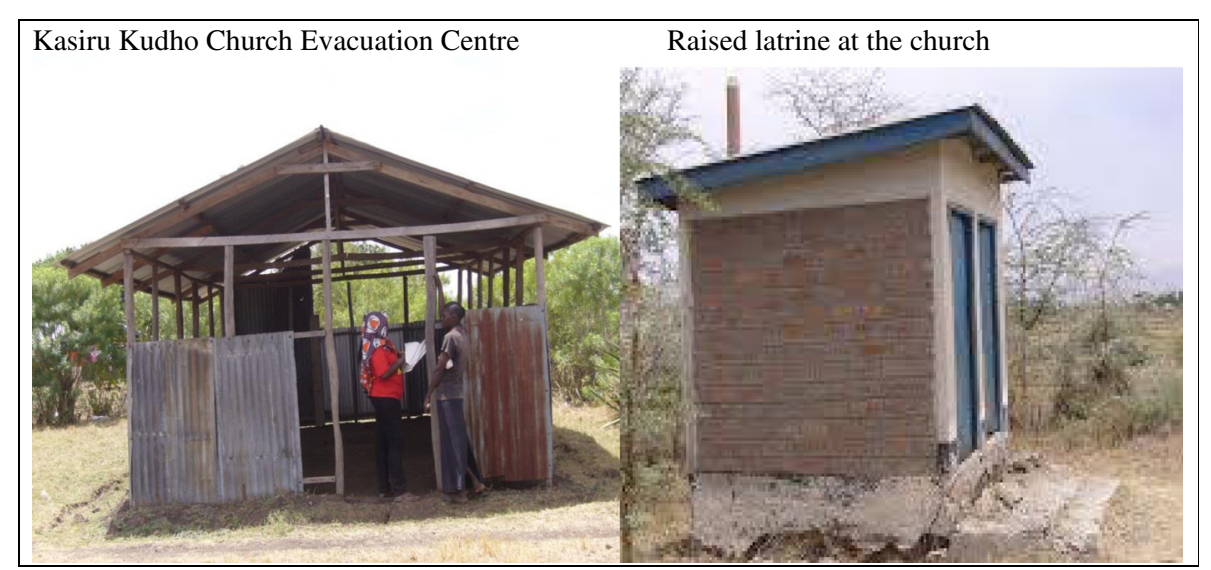

Fig. 7 Evacuation centre at Kasiru Kudho African Inland church with an improved latrine. The evacuation centre with a carrying capacity of 50 people is in a poor state; a health risk due to its small size and the gaping walls that allow mosquitoes to thrive during floods. However, an improved latrine by JICA, structural measure to mitigate the impact of floods, ensures that the raised latrine floor prevents filthy flood waters from overflowing the floor

The cold and mosquitoes cause pneumonia and malaria respectively.

At Achuodho centre, an FGD with Achuodho youth group also reveals a strong attachment to their land however muddy it is during the rainy season. They emphatically say:

We cannot leave to another site. We were born here; we wake up here and meet our neighbours in this surrounding. Where will we go to do casual work? We are used to the neighbourhood where we work as casual labourers in the sugar plantation.

There is evidence that the prohibiting factors to movement away from the risk zones are many: a) the community earns their living here; they need to or have no alternative to go. They grow rice here. River Nyando ensures some catch of fish during floods and the silt deposits especially around Wawidhi location (Nyando division) result in very fertile land for farming (healthy crops such as traditional vegetables: osuga, cowpeas, $d e k$, and mitoo etcetera. They supply women from the neighbouring Katito-Nyakach location with these vegetables during market days on Tuesdays and Thursdays at Ahero market. More or so, during drought, water that collects in the canals are used by cattle for growing food crops such as kales and fruits such as pawpaws and mangoes. b) culture prohibits movement: the village elders say they have been settled here since 1963, it is their land and there is fear of losing identity should they go elsewhere. At Achuodho and Rutek areas, the youth they cannot move because they are used to the muddy ground and that it will not be muddy for forever and they will always find their neighbours to talk and carry on with casual works they do around their homes; c) Even temporary relocation to evacuation centres such as
Achuodho, Kamagaga, and Kanyalwal is detested by many. These standard evacuation camps lack security and storage capacity. The community cites culture, gender insensitive and inhygienic evacuation centres, and theft of property if left unguarded at their flooded homesteads; and finally, d) inavailability of resources for moving their household goods.

The Kenya National Draft Disaster Policy stipulates that it is the duty of the government to protect its citizens from disasters (GOK, 2011). Even according to international humanitarian law, states have a responsibility not to cause any unnecessary suffering and to protect populations under their jurisdiction and control. So, the republic of Kenya is not exempted from the humanitarian law when it comes to disasters. In as much as flood disaster is the problem of the government, the community is the one that gets affected most; and they are the first responders to the impact of the disaster: lose lives, livelihood and property; affected by disease outbreaks and other factors. In conclusion therefore, it is evidenced that culture, gender insensitive evacuation centres, lack of resources and attitude of the community prohibit relocation for safety purposes to other areas during floods. The one thing that is certain is that the government will have less sustained impact if it does not adequately take account of people's cultures, beliefs and attitudes in relation to risk. Merely issuing warnings for people to go to higher grounds; and counties drawing budgets at desk committee meetings and setting aside millions of shillings to be used just when floods begin is not enough as the affected population is not involved in these activities or even in the planning. It shows how unprepared and reactive the government has always been in the face of disasters, more so, floods which had been hyped about several months ago. It defeats purpose why some county governments are building and/or yet to build dykes and 
dams now when floods are setting in! There is likely to be a lot of financial wastage if floods begin before the completion of infrastructure which might all the same be washed away if the structures are not strong enough to withstand the year's El Niño flood predicted to be the strongest since 1997-1998 and potentially among the four strongest events since 1950. The financial implication does not portend well for a country whose economy is unstable and dogged by debt. There is evidence that there is no proper prior planning for the flood, and there will be extreme losses which could have been avoided if the country had not adapted a wait-and see-attitude.

Motoyoshi (2006) says that recognition of costs has a strong negative effect on intention to participate. When people have a high recognition of costs, their intention to participate declines. On the other hand, recognition of benefits has only a small positive effect on intention to participate. As disasters do not occur frequently, people feel highly burdened to participate in community-based disaster preparedness activities during normal times when nothing happens. To activate community-based disaster preparedness activities, it is extremely important to reduce the public's recognition of costs.

\section{Social network}

Of those with low uptake, the highest percentage belonged to location-based network $77.1 \%$ (121), followed by $62.9 \%$ (39) social news services, then $50.45 \%$ (63) did not belong to any group, and lastly $50.0 \%$ (16) community building services (Table 3). A chi-square test shows that social network type was significantly associated with uptake of precautionary measures $(p>0.0001)$. The social network type helps in selecting approaches and tools appropriate to the different segments of the target audience. Dufty (2012) concurs that not only is appropriate individual participation required for disaster resilient communities, but also collective action. Several researchers believe that the formation of social capital is a critical factor in the ability of the community to quickly recover and 'bounce forward' after a disaster. These social networks, norms and social trust facilitate coordination and cooperation for mutual benefit. Reynaud et al. (2013) also confirm that one of the ways to mitigate flood impact could be through informal and social networks. In many developing countries informal networks play an important role, especially true under the threat of a natural disaster risk like a flood. The exchange of information or experiences about flooding helps in preparing to respond to another flood situation.

\section{Conclusions}

The study confirmed that high level of uptake of precautionary measures was not dependent on educational level of the household or the dominant construction material of wall of main house but was significantly dependent on distance, household composition, income, occupation of the household and social network type one belonged to. This means that during disasters, education level plays a very minimal role in determining protective behaviours of the affected population. What really matters to the population is responding to their individual needs first before anything else. Further research on household motivation for appropriate actions to mitigate floods should be conducted to better inform regional policy.

The study concludes that the community is complacent to flooding and how it impacts on them as long as relief is distributed to them. This is so because only a negligible number of the households are ready to move to higher ground, and that flood time is 'harvest' time. Even if asked to move, it is not clear where they will move and how they will survive there. Livelihoods, land resource, culture and attitude prohibit the community from relocating to other areas even during flooding. Inability to be proactive is also evidenced in the way the government adapts a last-minute rush to put structures in many counties to avert a possible threat of El Nino flood; a time when many government employees have not been paid salaries (e.g. teachers and members of parliament) and total public debt owed stands at Kshs.2.84 trillion.

The attitude of resignation and culture of 'wait-andsee' to a disaster risk if not checked will contribute to a build up of daily disaster emergencies in the country as flooding is increasingly getting worse due to urbanization and destruction of forest cover which results in climate change and its dire consequences on health and food security among others. Thus, expenditure on last -minute flood mitigation measures which are not sustainable will be bloated in all counties every flood season as has been identified.

\section{Recommendations}

\section{Policy recommendation}

This finding will contribute to the draft National disaster policy in the area of flooding that should specifically inform residents of the flood prone areas on how far away from the river that causes flooding should households be allowed to erect houses because some precautionary measures the households have employed involved moving to higher grounds. Stakeholders should thus emphasize specific messages targeted to residents who live close to the river because of the risk or danger to flooding. This would be one way of enforcing land use laws and regulations to discourage human encroachment into wetlands and flood plains (that act as buffers and filters of flood waters). 
In this study, there is evidence that culture operates in particular ways that affect people in their norms and assumptions about daily routines and practices. It influences what priorities should be and what action people should take in relation to risk (flood), and it must be understood and incorporated into any attempt to deal with natural hazards as it will affect any initiatives to deal with disaster risk reduction. However, traditional cultural dictates that make women more vulnerable in the face of disaster threats because of their lack of decision-making power in disaster prevention and preparedness should be discarded and empowerment of the victims to build resilience should be adopted as a mitigation strategy. So long as empowerment measures are economically suitable and address the present problems of the flood-prone community and future development(s) in the flood-prone land, then they should be adopted as a way of incorporating gender and cultural dimensions in the Kenya disaster policy.

There is need for continuous sensitization and preparation for flood disaster throughout the year. This can be done by creating structures in every county and monitoring performance based on set targets, and bearing in mind the unpredictability of disasters. The overall aim is to hold officers accountable to the government for exigencies dispatched to counties to mitigate impacts of floods with no evidence that precautionary measures have been taken in the vulnerable areas. Over-reliance on relief from the government should be fought vigorously; otherwise, the government will lose large sums of money to a community that is insensitive to its vulnerability to flood disaster and also unscrupulous hands. This study recommends a further research on physiological need versus resilience: motivation for disaster preparedness.

\footnotetext{
Abbreviations

AIDS: Acquired Immune Deficiency Syndrome; BBC: British Broadcasting Corporation; CBOs: Community Based Organizations; DANIDA: Danish International Development Agency; FBOs: Faith Based Organizations; FGDs: Focus Group Discussions; GFDR: Global Facility for Disaster Risk Reduction and Recovery; GOK: Government of Kenya; HFA: Hyogo Framework for Action; HBM: Health Belief Model; HIV: Human Immuno-deficiency Virus; JICA: Japan International Cooperation Agency; K.I.l: Key Informant Interview; KNBS: Kenya National Bureau of Statistics; KNDP: Kenya National Draft Disaster Policy; KRCS: Kenya Red Cross Society; NDOC: National Disaster Operation Centre; NEMA: National Emergency Management Authority; NGN: National Geographic News; NGOs: Non-Governmental Organizations; NIB: National Irrigation Board; OCHA: Organization for the Coordination of Humanitarian Affairs; PDNA: Post Disaster Needs Assessment; SSA: Sub-Saharan Africa; UN: United Nations; UNDP: United Nations Development Programme; UNEP: United Nations Environment Programme; UNICEF: United Nations Children Educational Fund; UNISDR: United Nations International Strategy for Disaster Risk Reduction; VIRED: Victoria Institute of Research and Development; WASH: Water, Sanitation and Hygiene; WDR: World Disasters Report; WFP: World Food Progamme; WMO: World Meteorological Organization.
}

\section{Competing interests}

The authors declare that they have no competing interests.

\section{Authors' contributions}

OJ developed the questionnaire, collected the data, performed the statistical analysis and drafted the manuscript. OP and OS, as supervisors, offered wise counsel and support throughout the entire $\mathrm{PhD}$ rearing process. They have offered invaluable guidance and helping hand.

\section{Authors' information}

The corresponding author, $\mathrm{OJ}$ is a PhD candidate at Masinde Muliro University of Science and Technology; Centre for Disaster Management and Humanitarian Assistance. This work majorly relied on the events and actions taken by respondents during period of flood disaster that happened in Kano Plains, Kenya in May 2013. Other data captured relied on the recall of year- to- year actions the respondents took to mitigate floods. The author thus, sought to find out the socio-economic characteristics of the flood-prone community of Kano Plains that influence their ability to uptake precautionary measures to mitigate the perennial floods.

$\mathrm{OP}$ is a Senior lecturer (Professor) at Masinde Muliro University of Science and Technology; in the department of Educational Psychology. He is currently the Dean, School of Graduate Studies. As my Supervisor, he has worked closely with me during my PhD work.

OS is also a Senior lecturer (Dr) at Masinde Muliro University, Centre for Disaster Management and Humanitarian Assistance, Acting Chair of Department of Disaster Management and Sustainable Development. He too supervised my PhD work.

\section{Acknowledgement}

This research has been conducted with the help from the Nyando sub-county officers, community policing officer and VIRED for offering an excellent working environment with pleasant and helpful people.

Received: 29 July 2015 Accepted: 17 November 2015

Published online: 25 November 2015

\section{References}

Achuka, V. 2015. Slum residents resign to fate as El Nino looms. Sunday Nation 2015: 26. in press.

Adedeji, $\mathrm{OH}, \mathrm{BO}$ Odufuwa, and $\mathrm{OH}$ Adebayo. 2012. Building capabilities for flood disaster and hazard preparedness and risk reduction in Nigeria: need for spatial planning and land management. Journal of Sustainable Development in Africa 14(1): 45-58.

Aloysius, B. 2012. Floods of fury in Nigerian cities. Journal of Sustainable Development 5(7): 69.

Atkin, CK, and V Freimuth. 2001. Formative evaluation research in campaign design. Public Communication Campaigns 3: 125-145.

Bakibinga-lbembe, JD, VA Said, and NW Mungai. 2011. Environmental laws and policies related to periodic flooding and sedimentation in the Lake Victoria Basin (LVB) of East Africa. African Journal of Environmental Science and Technology 5(5): 367-380.

Breaking News Kenya. 2015. Several Feared Dead after Flash Floods in Narok, Kenya (inpress)

British Broadcasting Corporation (BBC). 2007. Millions hit by floods in Africa.

Brody, SD, JE Kang, and S Bernhardt. 2010. Identifying factors influencing flood mitigation at the local level in Texas and Florida: The role of organizational capacity. Natural Hazards 52(1): 167-184.

Denga, FGO. 1990. The flood hazard in the lower reaches of the Sondu/Miriu River. Dissertation, University of Nairob

Dufty, N. 2009. Natural Hazards education in Australian schools: How can we make it more effective? The Australian Journal of Emergency Management 24(2): 13-16.

Dufty, N. 2012. Using social media to build community disaster resilience. The Australian Journal of Emergency Management 27(1): 40-45.

Gichere, SK, G Olado, DN Anyona, AS Matano, GO Dida, PO Abuom, J Amwayi, and VO Ofulla. 2013. Effects of Drought and Floods on Crop and Animal Losses and Socio-economic Status of Households in the Lake Victoria Basin of Kenya. Journal of Emerging Trends in Economics and Management Sciences (JETEMS) 4(1): 31-41. Scholarlink Research Institute Journals, 2013 (ISSN: 2141-7024).

Gathura, G. 2015. Kenyans adapt wait-to-see attitude despite global alarm. Daily Nation, 2015, National news, p8 (in press)

Gitonga, A. 2015. Kenya seeks Sh 10 b to reduce El Nino effects. The Standard, 2015, National News, p9 (in press) 
Government of Kenya (GOK). 2008. First Medium Term Plan (2008-2012), Kenya Vision 2030. A Globally Competitive and Prosperous Kenya. Ministry of state for planning, national development and vision 2030

Government of Kenya (GOK). 2009. Nyando District Development Plan 2008-2012: Kenya Vision 2030 towards a globally competitive and prosperous Kenya 2009

Government of Kenya (GOK). 2011. Kenya National Draft Policy, Ministry of State for Special Programmes

Government of Kenya (GOK). 2014. Kenya National Bureau of Statistics-Keeping you informed. Economic survey 2014. ISBN: 9966-767-47-9

Huho, JM, and Kosonei, RC. 2014. Understanding Extreme Climatic Events for Economic Development in Kenya. IOSR Journal of Environmental Science, Toxicology and Food Technology 8(2):14-24.

Karanci, AN, B Aksit, and G Dirik. 2005. Impact of a community disaster awareness training program in Turkey: Does it influence hazard-related cognitions and preparedness behaviors. Social Behavior and Personality 33(3): 243-258.

Kenya Disaster and Risk Profile. 2014. Preventionweb/ International disaster Database/basic country statistics and indicators

Kiel, LD. 1994. Managing Chaos and Complexity in Government; A new paradigm for Managing Change, Innovation and Organizational Renewal. San Francisco: Jossey-Bass.

Lindell, MK, and SN Hwang. 2008. Households' perceived personal risk and responses in a multihazard environment risk analysis, 28: 539-556. Doi: 10.1111/j.1539-6924.2008.01032.x

Mabatuk, V. 2015. Residents urged to relocate to safer grounds. The Standard Newspaper, 2015. p35 (in press)

Masibayi, E. 2011. Hydrologic and Hydraulic flood forecasting for Nzoia River Basin, Western Kenya. Dissertation, Masinde Muliro University

Macleod, AK. 2003. Cambodia Community-based Flood Mitgation and Preparedness Project

Mileti, DS, S Nathe, P Gori, M Greene, and E Lemersal. 2004. Public hazards communication and education: the state of the art. University of Colorado: Natural Hazards Center.

Motoyoshi, T. 2006. Public Perception of Flood Risk and Community-based Disaster Preparedness. A better integrated management of disaster risks: Toward resilient society to emerging disaster risks in megacities, Tokyo, Japan. Terrapub, 121-134

National Geographic News. 2007. Global warming in Africa.

Ngoran, SD, KE Dogah, and XZ Xue. 2015. Assessing the impacts of Climate Change on Water Resources: The Sub-Saharan Africa Perspective. Journal of Economics and Sustainable Development 6(1): 2015. ISSN 2222-1700(paper) ISSN 2222-2855 (Online).

Ngunjiri, J. 2015. Counties ask State to release El Nino funds. Daily Nation, 2015 p21 (in press)

Nyakundi, H, S Mogere, I Mwanzo, and A Yitambe. 2010. Community perceptions and response to flood risks in Nyando District, Western Kenya. Journal of Disaster Risk Studies 3(1): 346-366.

Nzuma, V. 2015. Mutua earmarks Shs. 300 m for El Nino response. The Standard, 2015, Counties p19 (in press)

Ocholla, PO. 2010. The Impact of Flooding Characteristics on Cotton Cultivation in Lower Kano Plain in Nyando District, Western Kenya. Dissertation, University of Kwa Zulu Natal

Omungu, BA. 2014. Impact of natural disasters on rural household poverty-A case study of floods in lower Kano plains, Kenya, dissertation, University of Nairobi.

Ongor, D. 2007. Integrating water resource management and flood management: A case study of the Nyando River watershed in Kenya. Catchment and Lake Research. Journal Las 007 Catchment and Lake Research: JICA Flood Management.

Onyango, D. 2015. Counties Prepare for safety as El Nino approaches. The Standard Newspaper, 2015. National News, p10 (in press)

Oppong, BK. 2011. Environmental hazards in Ghanaian cities: the incidence of annual floods along the Aboabo River in the Kumasi Metropolitan area of the Ashanti region of Ghana. Dissertation, Kwame Nkrumah University of Science and Technology.

Opondo, DO. 2013. Erosive coping after the 2011 floods in Kenya. International Journal GlobalWarming 5(4): 452-466.

Orengo, P. 2015. Government steps up disaster preparedness to contain floods. The Standard Newspaper, 2015 p10 (in press)

Otiende, B. 2009. The economic impacts of climate change in Kenya: riparian flood impacts and cost of adaptation. org/knowledge-base/files/758/ 4e25a4b8c8bf61C-kenyariparian-floods-case-study. Accessed August 2013

Owuor, M. 2007. Performing the last rites. Nairobi: The Standard Group.
Paul, BK, and RH Bhuiyan. 2010. Urban earthquake hazard: perceived seismic risk and preparedness in Dhaka City, Bangladesh. Disasters 34(2): 337-359.

Parker, DJ, SJ Priest, and SM Tapsell. 2009. Understanding and enhancing the public's behavioural response to flood warning information. Meteorological Application 16(1): 103-114.

Rea, LM, and RA Parker. 2012. Designing and conducting survey research: A comprehensive guide. New York: John Wiley \& Sons.

Reynaud, A, C Aubert, and MH Nguyen. 2013. Living with Floods: Protective behaviours and risk perception of Vietnamese households. The Geneva Papers on Risk and Insurance-Issues and Practice 38(3): 547-579.

Rosenstock, IM. 1974. Health Belief Model and Preventive Health behavior. Health Education Monographs 2: 354-386.

Shen, X. 2010. Flood Risk Perception and Communication within Risk Management in Different Cultural Contexts. A Comparative Case Study between Wuhan, China, and Cologne, Germany, Graduate Research Series vol. 1. Bonn: UNU-EHS.

Thurairajah, N, RD Amaratunga, and E Bichard. 2010. Engaging the public in anticipating and mitigating the effects of flooding: international perspectives.

Terumoto, K. 2006. Issues and attitudes of local government officials for flood risk management. In A Better Integrated Management of Disaster Risks: Toward Resilient Society to Emerging Disaster Risks in Mega-cities, ed. S Ikeda, T Fukuzono, and T Sato, 165-176. Tokyo: Terra Scientific Publishing Company.

UNDP. 2009. Building Disaster Resilient Communities, Good Practices and Lessons Learned, A Publication of the Global Network of NGOs for Disaster Risk Reduction

UNEP. 2006. UNEP Strategy for Environmental Education and Training A Strategy and Action Planning for the Decade 2005 - 2014.

UNISDR. 2012. United Nations international strategy for disaster reduction: Hyogo Framework for Action.

Wachira, M. 2015. Residents urged to help avert possible disaster, El Nino Watch 2015 Daily Nation. 22

World Disasters Report. 2014. Focus on culture and risk, 12.

Yande, PM. 2009. An impact of floods on the socio-economic livelihoods of people: A case study of Sikaunzwe Community in Kazungula District of Zambia. Dissertation, University of Free State.

\section{Submit your manuscript to a SpringerOpen ${ }^{\odot}$ journal and benefit from:}

- Convenient online submission

$\checkmark$ Rigorous peer review

- Immediate publication on acceptance

- Open access: articles freely available online

- High visibility within the field

- Retaining the copyright to your article

Submit your next manuscript at $>$ springeropen.com 